Published in "Cognitive Psychology 66(1): 1-29, 2013"

which should be cited to refer to this work.

\title{
Development of allocentric spatial memory abilities in children from 18 months to 5 years of age
}

\author{
Farfalla Ribordy ${ }^{\mathrm{a}, \mathrm{b}}$, Adeline Jabès ${ }^{\mathrm{c}}$, Pamela Banta Lavenex ${ }^{\mathrm{a}, \mathrm{b}, \mathrm{d}}$, \\ Pierre Lavenex ${ }^{\mathrm{a}, \mathrm{b}, \mathrm{d}, *}$ \\ ${ }^{a}$ Laboratory of Brain and Cognitive Development, Department of Medicine, University of Fribourg, 1700 Fribourg, Switzerland \\ ${ }^{\mathrm{b}}$ Fribourg Center for Cognition, University of Fribourg, 1700 Fribourg, Switzerland \\ 'Laboratories of Cognitive Neuroscience, Children's Hospital Boston and Harvard Medical School, Boston, MA, USA \\ ${ }^{\mathrm{d}}$ Institute of Psychology, University of Lausanne, 1015 Lausanne, Switzerland
}

\begin{abstract}
Episodic memories for autobiographical events that happen in unique spatiotemporal contexts are central to defining who we are. Yet, before 2 years of age, children are unable to form or store episodic memories for recall later in life, a phenomenon known as infantile amnesia. Here, we studied the development of allocentric spatial memory, a fundamental component of episodic memory, in two versions of a real-world memory task requiring 18 month- to 5 -year-old children to search for rewards hidden beneath cups distributed in an open-field arena. Whereas children 25-42months-old were not capable of discriminating three reward locations among 18 possible locations in absence of local cues marking these locations, children older than 43 months found the reward locations reliably. These results support previous findings suggesting that allocentric spatial memory, if present, is only rudimentary in children under 3.5 years of age. However, when tested with only one reward location among four possible locations, children 25-39-months-old found the reward reliably in absence of local cues, whereas 18-23-month-olds did not. Our findings thus show that the ability to form a basic allocentric representation of the environment is present by 2 years of age, and its emergence coincides temporally with the offset of infantile amnesia. However, the ability of children to distinguish and remember closely related spatial locations improves from 2 to 3.5 years of age, a developmental period marked by persistent deficits in long-term episodic memory known as childhood amnesia. These findings support the hypothesis that the differential maturation of distinct hippocampal circuits contributes to the emergence of specific memory processes during early childhood.
\end{abstract}

* Corresponding author at: Laboratory of Brain and Cognitive Development, Department of Medicine, University of Fribourg, Chemin du Musée 5, 1700 Fribourg, Switzerland. Fax: +41 263009734.

E-mail address: pierre.lavenex@unifr.ch (P. Lavenex). 


\section{Introduction}

Episodic memories for autobiographical events that happen in unique spatiotemporal contexts are central to defining who we are. Yet, prior to about two years of age, children are unable to form or store episodic memories for recall later in life, a phenomenon known as infantile amnesia (Bachevalier, 1992; Bauer, 2007; Nadel \& Zola-Morgan, 1984; Newcombe, Lloyd, \& Ratliff, 2007). The three to five years that follow this period are characterized by fewer episodic memories than would be predicted based on a simple forgetting function alone, a phenomenon referred to as childhood amnesia (Bachevalier, 1992; Bauer, 2007; Nadel \& Zola-Morgan, 1984; Newcombe et al., 2007). To date, the neurobiological bases for these phenomena have remained highly hypothetical (Bachevalier, 1992; Bauer, 2007; Nadel \& Zola-Morgan, 1984; Newcombe et al., 2007). In contrast, research conducted over the last 30 years has established that multiple memory systems are subserved by different brain circuits in adult individuals (Squire, 1992; White \& McDonald, 2002). In particular, declarative memory, which includes episodic memory and semantic memory (i.e., factual knowledge about the world), is dependent on the integrity and function of the hippocampal formation in adult humans (Milner, Squire, \& Kandel, 1998; Morris, 2007), whereas non-declarative memories are not (Squire, 1992). Allocentric spatial memory, the memory for locations coded in a relational manner to the surrounding environment, is a fundamental component of episodic memory, the "where" component of the defining "what, where and when" of episodic memories (Nyberg et al., 1996; Tulving, 2002). Like semantic and episodic memory, allocentric spatial memory is also dependent on the integrity and function of the hippocampus in adult individuals (Banta Lavenex, Amaral, \& Lavenex, 2006; Morris, Garrud, Rawlins, \& O'Keefe, 1982; O'Keefe and Nadel, 1978; Olton, Walker, \& Gage, 1978; Place et al., 2012; for a review of the theory of the general relational nature of the hippocampus, see Konkel \& Cohen, 2009), whereas egocentric spatial memory, the memory for locations coded in relation to the body such as "on my left", "on my right" or "in front of me", is not (Banta Lavenex \& Lavenex, 2009; Eichenbaum, Stewart, \& Morris, 1990; Rogers \& Kesner, 2006; Weniger \& Irle, 2006; Weniger, Ruhleder, Wolf, Lange, \& Irle, 2009). However, despite our ever-increasing comprehension of the role that the hippocampal formation serves in learning and memory in adult individuals, our understanding of how different memory systems develop and why different types of hippocampus-dependent memory emerge when they do in early childhood is much less complete (see Bauer, 2007; Newcombe et al., 2007 for reviews). Here, we studied the development of allocentric spatial memory, a fundamental component of episodic memory, in children from 18 months to five years of age in order to shed light on infantile and childhood amnesia and the development of hippocampus-dependent memory processes in children.

The ability of infants and toddlers to remember the location of an object in an egocentric frame of reference has been extensively studied, and performance has been shown to depend on a number of factors including the age of the child, the length of the delay between hiding and finding, and the amount of pre-training (which can bias the infant towards egocentric responding) the child receives (see Newcombe \& Huttenlocher, 2000 for a review). In contrast, although the emergence and maturation of allocentric spatial memory abilities in children has also been extensively studied, the majority of studies have yielded disparate and seemingly conflicting results with respect to when spatial competence emerges and matures in children. An important exception, however, is one study by Newcombe and colleagues reporting that from 22 months of age children demonstrate the ability to use allocentric spatial information (Newcombe, Huttenlocher, Bullock Drummey, \& Wiley, 1998). Children watched while a small plastic toy was buried in a sandbox. Half of the children were tested with access to distal visual cues in the room during hiding and retrieval, whereas the other half did not have access 
to distal visual cues because opaque curtains surrounded the experimental apparatus. After being asked to turn around and look briefly at their parent who was located behind them (in order to break eye contact with the hiding location), children were guided to the opposite side of the sandbox where they were asked to search for the toy under the smooth sand surface. Children older than 22 months of age benefited from the presence of the distal visual cues to increase search accuracy, whereas younger children did not. Unfortunately, however, because Newcombe's article (Newcombe et al., 1998) does not present a picture or detailed description of the testing room detailing the proximity and location of objects in the room, it is not entirely possible to rule out children's ability to use a visual guidance strategy to solve this task. Although visual cues are critical to creating an allocentric representation of the environment for most sighted individuals (including macrosmatic animals such as rats; Lavenex \& Schenk, 1996), it is important to distinguish between (1) distal visual cues that are used in a relational manner to construct an allocentric representation of the environment including the location of the subject and the goal location relative to other objects in the environment, and (2) local and distal visual cues that can be used in a simple associative manner to define a goal location (henceforth referred to as a visual guidance strategy). For example, if a goal location can be visually associated with a single object (such as "the location closest to the desk" or "when viewed from the doorway, it is the location visually aligned with the window"), then memory for the spatial location itself is no longer necessary in order to localize the goal. Indeed, since visual guidance strategies require only a simple association, they may be utilized preferentially to egocentric or allocentric encoding whenever possible, or whenever necessary as in the case of subjects incapable of using allocentric encoding. Nevertheless, we believe that for the case of Newcombe et al. (1988) it is unlikely that children used visual guidance strategies to localize the hidden toy because their viewpoint during retrieval was shifted by $180^{\circ}$ from the viewpoint that they had during hiding, thus making a simple visual association between any single object in the room and the goal location improbable. One could argue that, in the curtainless condition, children took advantage of a nearby object, such as a desk, to make a more accurate distance estimation of the goal location. If this was the case, however, then the side of the sandbox or the curtain itself should have sufficed for older children to make such an estimation in the curtained condition, and their performance should not have improved in the curtainless condition. Thus, although not definitive, the results of Newcombe et al. (1998) are highly suggestive that children older than 22 months can use an allocentric spatial representation of their environment to define a goal location.

To date, however, no other studies have succeeded in unequivocally demonstrating allocentric spatial capacities in children under three years of age. For example, DeLoache and Brown reported that 18-22-month-old children were capable of discriminating which box, amongst four identical boxes arranged in rectangular formation, hid a toy (DeLoache \& Brown, 1983). However, because children could always approach the boxes from the same place in the room, the possibility that children used an egocentric strategy to solve this task cannot be excluded. Indeed the children's success rate, around $50 \%$, is consistent with the use of an egocentric (left/right) strategy. A study by Balcomb, Newcombe, and Ferrara (2011) evaluated children's abilities to solve a Morris search task, and suggested that allocentric spatial abilities emerge around 24 months of age. However, because objects surrounding the circular arena could provide distinctive visual guidance cues, and children were always released from the center of the arena, allowing them to encounter a standardized view of the goal location, the use of visual guidance strategies by children cannot be ruled out. Numerous studies have investigated children's capacities in the radial arm maze, but have reported either equivocal findings or that spatial competence emerges much later. For example, Foreman and colleagues suggested that 2-year-olds ( $n=4$; mean age 26 months) might exhibit above chance performance in a free-choice paradigm (Foreman, Arber, \& Savage, 1984); but in a later study, another group of 2-year-olds ( $n=5$ : mean age 23.2 months) did not (Foreman, Warry, \& Murray, 1990). Aadland and colleagues also reported that the performance of a group of children under 30 months ( $n=7$; range 18 to 30 months) was slightly above chance (defined as $45 \%$ correct for choices $5-8$ ) in a free-choice paradigm, but none of the children met a criterion of entering 7 different arms on the first 8 choices or completing 20 trials (Aadland, Beatty, \& Maki, 1985). Finally, in a study by Overman and colleagues the performance of 2 -year-olds ( $n=6$; range $20-30$ months) varied between approximately $37 \%$ and $75 \%$ correct arm selection in the first eight choices of a free-choice paradigm (Overman, Pate, Moore, \& Peuster, 
1996). Although these data are suggestive that 2-year-olds possess a certain level of allocentric spatial competence, it is critical to consider the fact that age-dependent improvements in performance in the free-choice paradigm of the radial arm maze are often associated with a change in foraging strategy by children who begin visiting adjacent arms (Aadland et al., 1985). Indeed, a spatial strategy which relies on choosing adjacent arms does not require reliance on a memory of the arms' spatial locations (Lavenex \& Schenk, 1996), thus questioning the conclusions that can be derived from spatial memory experiments performed with a free-choice paradigm in the radial arm maze. Perhaps more importantly, few studies implementing the radial arm maze in children have controlled for extramaze visual cues, as described above for the Balcomb et al. (2011) study. For example, mazes were placed either in a room, where individual arms could be associated with visually distinctive objects that were located directly behind the arm (such as windows, doors, radiators, and cupboards; Aadland et al., 1985; Foreman et al., 1984, 1990), or outdoors, where distinctive distal cues might be aligned with specific arms (such as buildings, trees, and parking areas; Overman et al., 1996), especially when participants were required to return to the center of the maze before choosing the next arm (thus allowing them a standardized view of each arm). When carried out under such conditions, the possibility that children can use a visual guidance strategy to identify specific maze arms cannot be ruled out (see Section 4.1 Task specificity for further discussion).

The majority of other studies have restricted their investigations of allocentric spatial capacities to children three years and older, and these studies have repeatedly shown that (1) the performance of 3year-olds on allocentric spatial tasks is inferior to that of older children; (2) children show marked improvement in their allocentric capacities between four and six years of age; and (3) for most of the tasks employed, children's performance becomes adult-like sometime between seven and ten years of age (Bullens et al., 2010; Foreman et al., 1984, 1990; Lehnung et al., 1998; Leplow et al., 2003; Mandolesi, Petrosini, Menghini, Addona, \& Vicari, 2009; Nardini, Burgess, Breckenridge, \& Atkinson, 2006; Overman et al., 1996; Pentland, Anderson, Dye, \& Wood, 2003; Smith et al., 2008). Thus, with the possible exception of Newcombe's study (Newcombe et al., 1998), no study has unequivocally demonstrated that children under three years of age are capable of solving a task which requires the use of an allocentric spatial representation, a fundamental component of episodic memory.

One possible reason for this is the fact that for the majority of the tasks previously used to investigate spatial memory in children, optimal performance is also dependent on the maturation of other cognitive processes. Specifically, in order to solve the commonly-used radial arm maze (Aadland et al., 1985; Foreman et al., 1984, 1990; Mandolesi et al., 2009; Overman et al., 1996), participants must rely not only on their allocentric spatial memory to discriminate one arm from another, but also on their working memory to remember which arms they have already visited on any given trial (unless they solve the task by visiting immediately adjacent arms, see above). As working memory proficiency increases with age (Dempster, 1981; Gathercole, 1998; Hitch \& Halliday, 1983; Siegel \& Ryan, 1989), this may confound the results and interpretation of spatial memory experiments performed in the radial arm maze. It is also the case that the radial arm maze requires subjects to implement a win-shift strategy (i.e., avoid previously visited locations; Gaffan \& Davies, 1981; White \& McDonald, 2002), which itself has been shown to be less developed in 19-month-olds as compared to 36-month-olds (Cornell, Heth, Broda, \& Butterfield, 1987). Finally, other spatial memory tasks also incorporate designs which necessitate other cognitive capacities, such as the ability to perform mental rotation (Nardini et al., 2006) or advanced linguistic and cognitive capacities in order to understand the researcher-defined goal of the task (Acredolo, 1977; Lehnung et al., 1998; Leplow et al., 2003; Nardini et al., 2006). The contribution of these other cognitive capacities to task performance potentially confounds the interpretation of the development of allocentric spatial memory capacities with that of other cognitive capacities.

Here we tested children from 18 months to 5 years of age on two versions of a hippocampusdependent real-world spatial memory task (Banta Lavenex \& Lavenex, 2009) that we previously used to investigate spatial memory capacities in rats (Lavenex \& Schenk, 1995, 1997, 1998), free-ranging squirrels (Lavenex, Shiflett, Lee, \& Jacobs, 1998), intact and hippocampal-lesioned freely moving infant and adult monkeys (Banta Lavenex et al., 2006; Lavenex \& Banta Lavenex, 2006; Lavenex, Banta Lavenex, \& Amaral, 2007) and intact and hippocampal-lesioned adult humans (Banta Lavenex \& 
Lavenex, 2010; unpublished data). Importantly, our task specifically assesses allocentric spatial memory, and precludes success that arises from using an egocentric strategy (Banta Lavenex \& Lavenex, 2009). Moreover, our paradigm does not require participants to follow specific verbal instructions or rely on other cognitive capacities (such as working memory, episodic-like trial-unique memory, win-shift strategies, or mental rotation), in order to demonstrate allocentric spatial memory competence.

\section{Experiment 1}

\subsection{Methods}

\subsubsection{Participants}

Participants were 44 children (24 males, age range 25.8-61.8 months; 20 females, age range 31.559.3 months). Sixteen of the 44 children (denoted by the letter a in Table 1 ) had participated nine months earlier in a pilot study that investigated their ability to solve a similar spatial task (with 18 potentially rewarded locations, and six regularly arranged goal locations; none of the goal locations were the same as those used in this study). Participants were recruited via email postings to the University of Fribourg faculty and staff, and via flyers distributed to parents in local neighborhoods and mailed to pediatricians' offices and daycare centers. Participants were tested during two sessions of approximately 45 min each, which took place in general on two consecutive days, but depending on the participant's availability may have been separated by an interval of up to 4 days. Testing took place Monday through Friday, between 8 A.M. and 6:30 P.M. Human subjects research was approved by the Intercantonal Ethics Committee for Jura, Neuchatel, Fribourg (protocol No. 10/2007), and the Ethical Commission for Clinical Research in Vaud (protocol No. 38/08), and was in accordance with the NIH guidelines for the use of human subjects in research. The parents of all participants gave informed written consent.

\subsubsection{Testing facility}

We had testing facilities in two different locations (i.e., in different towns in Switzerland); 21 children were tested in the canton of Vaud, and 23 in the canton of Fribourg. We found no differences in the behavior or performance of the children tested in these two different locations, and therefore data gathered at these two sites were grouped for analysis and presentation. The main features of the testing facilities were consistent between the two testing sites. Testing took place within large rectangular rooms (Vaud: $9 \mathrm{~m} \times 6 \mathrm{~m}$, Fig. 1; Fribourg: $7 \mathrm{~m} \times 6 \mathrm{~m}$, Fig. 4) containing many polarizing features such as doors, obscured windows, tables, chairs, and wall posters. Within the room, we placed a $4 \mathrm{~m} \times 4 \mathrm{~m}$ testing arena that consisted of 3 walls made of suspended, opaque plastic curtains ( $2 \mathrm{~m}$ high). Whereas the curtain on the back wall was $4 \mathrm{~m}$ wide, the curtains on the side walls extended only $3 \mathrm{~m}$, so that there was a $50 \mathrm{~cm}$ gap at the front and the back of the wall, thus creating four different entry points through which participants passed in order to enter and exit the testing arena. Each entry point was marked by a number (1-4) on the inside and outside walls next to the door. The fourth (front) boundary between the testing arena and the experimental room was delineated by a rope attached to the two opposing sides of the arena, and suspended $30 \mathrm{~cm}$ off the ground. Exterior to the two side walls, the inter-trial waiting area was a corridor ( $1 \mathrm{~m}$ wide $\times 4 \mathrm{~m}$ long) that contained two chairs with their backs to the arena wall, and various items including a trash can, occluded windows, doors, child-oriented posters, etc., none of which could be viewed from within the arena. Importantly, from within the arena, and from the inter-trial waiting area, participants had access to distant visual cues within the room. The arena floor in Vaud was covered with a solid dark blue carpet; the floor in Fribourg was covered with a uniformly-speckled linoleum. There were no distinguishing marks or lines on the flooring that could be used as visual guidance cues.

The testing arena was void of all objects except for 18 symmetrically arranged white paper plates $(18 \mathrm{~cm}$ in diameter) that were arranged in a regular pattern that resembled two concentric hexagons: an inner hexagon consisting of six locations, and an outer hexagon consisting of 12 locations (Fig. 1); the center of the hexagon was empty. An inverted opaque plastic cup ( $7.5 \mathrm{~cm}$ in diameter, $6.5 \mathrm{~cm}$ high) 
Table 1

Performance of individual children in Experiment 1 with three reward locations among 18 possible locations.

\begin{tabular}{|c|c|c|c|c|c|c|c|}
\hline \multicolumn{2}{|c|}{ Participants } & \multicolumn{6}{|c|}{ Locations discriminated in: } \\
\hline \multirow[b]{3}{*}{ Age (mo) } & \multirow[b]{3}{*}{$\mathrm{M} / \mathrm{F}$} & \multirow{2}{*}{\multicolumn{2}{|c|}{$\begin{array}{l}\text { Local cue condition } \\
\text { First } 3 \text { locations searched }\end{array}$}} & \multicolumn{4}{|c|}{ Allocentric spatial condition } \\
\hline & & & & \multicolumn{2}{|c|}{ First location searched } & \multicolumn{2}{|c|}{ First 3 locations searched } \\
\hline & & No & Yes & No & Yes & No & Yes \\
\hline $25.8^{\mathrm{a}}$ & M & & $\mathrm{X}$ & $\mathrm{X}$ & & $\mathrm{X}$ & \\
\hline$\overline{29.4}$ & M & & $\mathrm{X}$ & $\mathrm{X}$ & & $\mathrm{X}$ & \\
\hline$\underline{31.5}$ & $\mathrm{~F}$ & & $\mathrm{X}$ & $\mathrm{X}$ & & $\mathrm{X}$ & \\
\hline 34.2 & $\mathrm{~F}$ & & $\mathrm{X}$ & $\mathrm{X}$ & & $\mathrm{X}$ & \\
\hline 34.5 & $\mathrm{~F}$ & & $\mathrm{X}$ & $\mathrm{X}$ & & $\mathrm{X}$ & \\
\hline 34.9 & M & & $\mathrm{X}$ & $\mathrm{X}$ & & $\mathrm{X}$ & \\
\hline 35.1 & $\mathrm{~F}$ & & $\mathrm{X}$ & $\mathrm{X}$ & & $\mathrm{X}$ & \\
\hline 35.5 & $\mathrm{~F}$ & & $\mathrm{X}$ & & $\mathrm{X}$ & & $\mathrm{X}$ \\
\hline 36.3 & M & & $\mathrm{X}$ & $\mathrm{X}$ & & $\mathrm{X}$ & \\
\hline $36.4^{\mathrm{a}}$ & M & & $\mathrm{X}$ & $\mathrm{X}$ & & $\mathrm{X}$ & \\
\hline $36.4^{\mathrm{a}}$ & M & & $\mathrm{X}$ & $\mathrm{X}$ & & $\mathrm{X}$ & \\
\hline $36.7^{\mathrm{a}}$ & $\mathrm{F}$ & & $X$ & $X$ & & $X$ & \\
\hline 37.4 & M & & $X$ & & $\mathrm{X}$ & & $\mathrm{X}$ \\
\hline 38.4 & M & & $X$ & & $X$ & & $\mathrm{X}$ \\
\hline 38.9 & $\mathrm{~F}$ & & $X$ & $\mathrm{X}$ & & $X$ & \\
\hline 39.5 & $\mathrm{~F}$ & & $X$ & $X$ & & $X$ & \\
\hline 41.8 & M & & $X$ & $X$ & & $X$ & \\
\hline 43.7 & $\mathrm{~F}$ & & $X$ & & $X$ & & $X$ \\
\hline 46.2 & M & & $X$ & & $X$ & & $X$ \\
\hline 46.3 & M & & $X$ & & $X$ & & $X$ \\
\hline 46.3 & $\mathrm{~F}$ & & $X$ & & $X$ & & $X$ \\
\hline 46.4 & M & & $\mathrm{X}$ & & $\mathrm{X}$ & & $\mathrm{X}$ \\
\hline 46.5 & $\mathrm{~F}$ & & $\mathrm{X}$ & & $\mathrm{X}$ & & $\mathrm{X}$ \\
\hline 47.2 & M & & $X$ & & $X$ & & $X$ \\
\hline 47.4 & $\mathrm{~F}$ & & $X$ & & $X$ & & $X$ \\
\hline 48.0 & $\mathrm{~F}$ & & $X$ & & $X$ & & $\mathrm{X}$ \\
\hline $48.4^{\mathrm{a}}$ & M & & $X$ & & $X$ & & $X$ \\
\hline $50.4^{\mathrm{a}}$ & $\mathrm{F}$ & & $X$ & & $X$ & & $X$ \\
\hline $50.8^{\mathrm{a}}$ & F & & $X$ & & $X$ & & $X$ \\
\hline 50.9 & $\mathrm{~F}$ & & $X$ & & $X$ & & $X$ \\
\hline $52.3^{\mathrm{a}}$ & M & & $X$ & & $X$ & & $\mathrm{X}$ \\
\hline $54.1^{\mathrm{a}}$ & M & & $X$ & & $X$ & & $X$ \\
\hline $54.7^{\mathrm{a}}$ & M & & $X$ & $X$ & & & $X$ \\
\hline 54.9 & $\mathrm{~F}$ & & $\mathrm{X}$ & & $X$ & & $\mathrm{X}$ \\
\hline 55.3 & $\mathrm{~F}$ & & $X$ & & $X$ & & $X$ \\
\hline 56.4 & $\mathrm{~F}$ & & $X$ & & $X$ & & $X$ \\
\hline $56.5^{\mathrm{a}}$ & M & & $X$ & $X$ & & $X$ & \\
\hline $57.2^{\mathrm{a}}$ & M & & $\mathrm{X}$ & & $X$ & & $X$ \\
\hline 59.3 & $\mathrm{~F}$ & & $X$ & & $X$ & & $X$ \\
\hline $59.8^{\mathrm{a}}$ & M & & $X$ & & $X$ & & $X$ \\
\hline $60.6^{\mathrm{a}}$ & M & & $X$ & & $X$ & & $X$ \\
\hline 61.0 & M & & $\mathrm{X}$ & & $X$ & & $X$ \\
\hline$\underline{61.5}^{\mathrm{a}}$ & M & & $\mathrm{X}$ & & $X$ & & $X$ \\
\hline$\overline{61.8^{a}}$ & M & & $X$ & & $X$ & & $X$ \\
\hline
\end{tabular}

UNDERLINE: results not included in learning curve analysis (See Section 2.2.2).

a Participated in pilot experiment 9 months prior.

was placed on each paper plate. Three food rewards were hidden in an asymmetrically-distributed pattern within the arena, at locations 7, 10 and 14. Importantly, each of the 18 designated locations in the arena was uniquely defined by its relations with distal objects located in the testing room.

Participants had to lift or turn over the plastic cups to obtain the hidden food. Rewards were

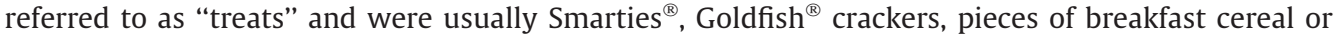


A

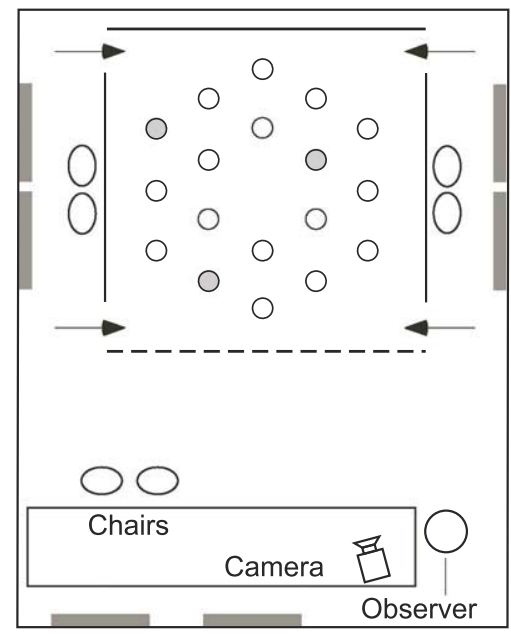

B

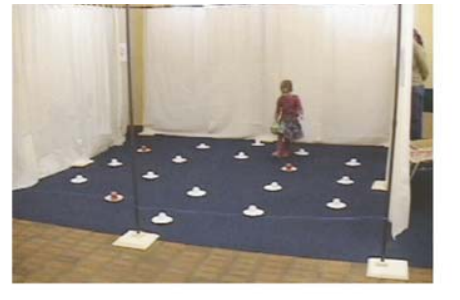

D

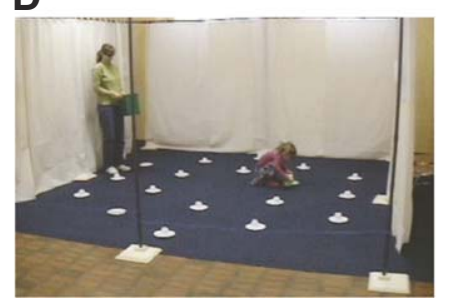

C

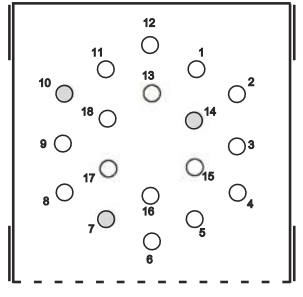

E

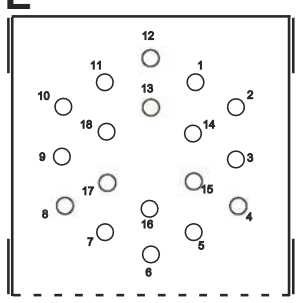

Fig. 1. Experimental setup. (A) Schematic of the testing room $(9 \mathrm{~m} \times 6 \mathrm{~m})$ and the arena $(4 \mathrm{~m} \times 4 \mathrm{~m})$, including tables, chairs, and posters/obscured windows/doors (gray rectangles). (B) Picture of a participant in the arena in the local cue condition (LC). (C) Schematic of the LC condition. (D) Picture of a participant in the arena in the allocentric spatial condition (AS). (E) Schematic of the AS condition.

pretzels. Occasionally, small stickers served as rewards for children that were not interested in food rewards. All parents were queried with respect to alimentary allergies prior to any testing. All testing was videotaped with a video camera located in front of the testing arena.

\subsubsection{Testing procedure}

All testing involved a team of two experimenters. Experimenter 1 (E1) would stay with the child throughout the testing session and would enter the arena with the child, encourage the child to search for the hidden rewards, verbally praise the child when a reward was found, pick up cups that had been searched by the children and place them in a plastic bucket that she carried, direct the child to the correct exit at the end of the trial, and occupy the child during the inter-trial interval by reading or talking. Experimenter 2 (E2) was responsible for replacing the rewards between trials, recording the data, and announcing the correct entry and exit doors.

Before testing began, children were free to view the arena with the 18 arranged plates (no inverted cups were present), from in front of the arena. E1 then showed the child a reward item on a paper plate that she held in her hand. While the child was watching, E1 would lower a plastic white cup (identical to those used during testing) over the treat to hide it. The child would then be asked "Where is the treat? Can you show me where it is?" When the child lifted the cup to expose the treat, they would be verbally praised and told that the treat was theirs to eat (or save in a small plastic bag for later).

Once the child had been shown that a treat could be found underneath the plastic cup, the child and E1 would go to the predetermined side of the arena where testing would begin. If children were reluctant to go alone with E1, the child's accompanying adult (parent, grandparent, care provider, henceforth referred to as the parent) would be asked to join the experimenter and the child. Once the child was behind the curtain and occupied, E2 would hide a treat in each of the three predetermined rewarded locations (locations 7, 10 and 14; Fig. 1C and E). Because three locations were rewarded, three different treat types would be hidden on each trial (i.e., one Smarties ${ }^{\circledR}$, one piece of cereal, one piece of pretzel). Thus, children would not find only one type of reward (and thus eat too many Smarties ${ }^{\circledR}$, for example), nor would they be able to predict what reward they would find, thus maintaining a high level of motivation. Food rewards were distributed pseudo-randomly at the 
three rewarded locations, ensuring, for example, that Smarties ${ }^{\circledR}$ were not always hidden at the same location trial after trial.

Children completed between 10 and 15 trials per day (explained below). Trials were of two different types: (1) Local Cue trials (LC), in which a local cue, specifically a red cup, covered the food rewards, whereas all other non-rewarded locations were covered with white cups. This condition allowed us to gauge children's overall motivation to participate, as well as to test each child's ability to find rewards at spatially fixed locations marked by local cues (red cups). In this condition, children could find and remember the reward locations either by associating the presence of the local cue with the reward, or by remembering the absolute spatial locations of the rewards based on their relations to distal environmental objects. In general, children received 5 LC trials on Day 1 and 3 to 5 LC trials on Day 2 (depending on their performance, see below). (2) Allocentric Spatial trials (AS), in which no local cues marked the reward locations, as identical white cups covered all locations. In this case, children could not discriminate between the rewarded and the never-rewarded locations based on local features. Instead, children had to rely on an allocentric, spatial representation of the environment to discriminate these locations, i.e., coding the absolute goal locations in relation to distal environmental objects. In general, children received 5 AS trials on Day 1 and 5 to 7 AS trials on Day 2 (but 4 children received 9 AS trials on Day 2, see Section 2.1.4, for specific details). In total, across both days, children received between 16 and 24 trials (mean $=20.3 \pm 1.4$ ). $\mathrm{LC}$ and $\mathrm{AS}$ trials were alternated $\left(\mathrm{LC}_{1}, \mathrm{AS}_{1}, \mathrm{LC}_{2}\right.$, $\left.\mathrm{AS}_{2}, \ldots, \mathrm{LC}_{10}, \mathrm{AS}_{10}\right)$. The first trial of Day 2 was a probe trial $(\mathrm{P})$ in the allocentric spatial condition to test children's long-term $(24 \mathrm{~h})$ memory for the reward locations; the three same locations were rewarded as usual. After that, LC and AS trials continued in the same alternating manner as for the first day.

Our goal was to determine whether children possessed the capacity to utilize an allocentric, spatial representation of the environment in order to identify the reward locations. However, when working with human participants in general, and children in particular, it is important to ensure that the participants understand the goals of the task as defined by the researcher. Even though we have previously shown that adults need no verbal instructions to understand the goal of our task and to exhibit successful performance (Banta Lavenex \& Lavenex, 2010), a pilot study had shown that older children (48-60 months) were very uncomfortable not receiving any kind of verbal instruction or feedback, and were in fact performing worse than younger children (30-45 months) who seemed to have no problem understanding the goal of the task (i.e., find rewards at fixed spatial locations). Interestingly, Overman and colleagues found very similar results in a Morris search task (Overman et al., 1996). When not given information about the static nature of the goal location, 4-year-olds performed worse than 3-year-olds. However, under the exact same conditions, but after being told that the goal location could always be found in the same place, their performance improved, and was equal to that of 3-yearolds (Overman et al., 1996). Thus, in order to give all children the greatest possibility of succeeding, they were given specific verbal instructions and as much feedback/encouragement as possible (as language comprehension is age-dependent, we consider possible implications that these verbal instructions may have had on performance in Section 4.2). Specifically, upon entering the arena on the first trial, E1 would explain to the child that he was going to see some cups, and that if he looked under the cups he would find some treats. At this point, most children would begin to slowly lift cups one-by-one until they found the treats. If the child was reluctant to lift the cups (which was occasionally the case for the first one to four trials), E1 or the child's parent (who sometimes had to accompany the child in the arena for the first few trials on the first day) would help the child to lift the cups ("Do you want me to lift the first cup for you?" "Show me which cup you want me to lift," etc.). Once a location was searched, E1 would provide verbal feedback. Verbal instruction/feedback did not vary in quantity or meaning between younger and older children, but rather in the complexity of the sentence structure. For example, older children might be told: "Congratulations! You found the treat! You will always find a treat here." Or, "Oh no, too bad. You will never find a treat here." Younger children received similar, although simpler feedback "Yeah! Always here! This is a good plate!" or "Oh no. Never here. This is a bad plate." Or sometimes just "Yes, yes," or "No, no" while pointing at the location a child had just searched.

Although many children had a tendency to spontaneously continue to lift other unrewarded cups after they had found the rewards, if they did not, they were encouraged to do so by E1 (at least for the 
first 2 or 3 trials) in order to make sure that the child understood the rules of the game (i.e., which locations hid rewards and which ones did not, and that these locations remained consistent from trial to trial). Indeed, in accordance with findings from our previous study using this same task with adults, it is critical to let participants explore without penalty as much as they feel necessary, in order to preclude them from exploring before choosing the correct locations, thus confounding their natural desire to explore in order to verify their response and/or the rules of the game (i.e., "is the experimenter trying to trick me?") with their real performance on the task. This exploratory behavior is observed across species, including birds (Pravosudov, Lavenex, \& Omanska, 2005), rodents (Lavenex \& Schenk, 1995, 1996, 1997, 1998; Lavenex et al., 1998), monkeys (Banta Lavenex et al., 2006; Lavenex \& Banta Lavenex, 2006; Lavenex et al., 2007) and humans (Banta Lavenex \& Lavenex, 2010).

Although children were given as much verbal instruction, encouragement and praise as possible in order to help them understand the task, they were never told or shown where the reward locations were, or how to identify them. Specifically, they were never told that when the red cups were present they could find the rewards there, nor were they verbally alerted by the experimenters to spatial relations between distal objects in the room and the reward locations.

Although parents were allowed to accompany children during trials if the children insisted, by the second day, all children would enter the arena and choose which cups to search independently, while their parent (if still requested by the child to accompany them during the inter-trial interval) watched from one of the entry doors on the same side of the arena that the child had just entered. Both experimenters, and any accompanying adults, wore dark sunglasses while the child was in the arena in order to avoid unintentionally cuing the child as to the locations of the rewards with eye gaze (Pepperberg, 1981).

As described above, there were four entries and exits to the arena. Entry order was determined in a pseudo-random manner, with respect to the following conditions: (1) All entrances should be used an equal number of times in the two conditions (LC and AS conditions) across the two days; (2) Children may never enter the arena through a door which they had just exited on the immediately preceding trial (to preclude the use of egocentric strategies); (3) Two successive trials should never have the same entry; and (4) All entries must be made from the same side (right or left) that the child just exited on the previous trial (i.e., children were not moved from one side of the arena to the other between trials). At the end of the trial, E2 would call out the appropriate exit number, and E1 would guide the children to that exit by pointing or by heading there first (all children were required to walk to and through the exit on their own and were never led by taking their hand), therefore ensuring that the children were on the appropriate side of the arena for the next trial. Children were thus constantly moving about the arena from trial to trial, entering and exiting on different sides, and at the back or front of the arena. Moreover, no environmental landmarks, such as doors, windows or furniture, could be found adjacent to or directly behind any of the reward locations (with the exception of the red cups in the LC condition). Consequently, in order to identify the reward locations in the absence of the local cues, children must rely on an allocentric, spatial representation of their environment (for further discussion, see Section 4.1 Task specificity; Banta Lavenex \& Lavenex, 2009, 2010).

\subsubsection{Data analysis}

All statistical analyses were performed with SPSS 16.0 statistical software. Because measures such as a child's speed, distance travelled, or their initial trajectory to the goal location might be influenced not only by factors such as age and size, but also by confidence, strategy, and motivation (i.e., the learning-performance distinction problem, Cahill, McGaugh, \& Weinberger, 2001; Rudy, 2008; Tolman \& Honzik, 1930), we assessed spatial competence by determining whether each individual child discriminated the rewarded locations from the never-rewarded locations, thus demonstrating whether that child "knew" where the rewards were hidden (Banta Lavenex \& Lavenex, 2010). To assess children's ability to discriminate the rewarded locations from the never-rewarded locations in the LC and AS conditions, we classified as "correct" or "incorrect" the first location, and the first three locations, that each child chose to search during each trial. For each analysis, we normalized the number of choices of a particular type based on the probability to make that choice: The number of choices of correct (rewarded) locations was divided by 3 and the number of choices of incorrect (never-rewarded) locations was divided by 15 (Banta Lavenex \& Lavenex, 2010). Because children 
were learning the rules of the task during the first one or two trials in each condition, we used the last 8 trials in each condition for these individual statistical analyses (i.e., generally the last 3 trials from Day 1 and all 5 trials from Day 2). However, because we wanted children to have every opportunity to succeed, those who had demonstrated that they could find the reward locations in the LC condition, but only appeared to have learned the reward locations on the second day, could be given 1-4 extra trials in the AS condition in order to increase their chance of demonstrating their success statistically (based on the last eight trials in the AS condition). In order to minimize the number of trials that children experienced, and since most of these children were already performing perfectly in the LC condition, we could replace 1 or 2 of their last LC trials of Day 2 with AS trials. For others, 2-4 AS trials were added after the last regularly scheduled AS trial 5 on Day 2 . Thus, when children were given extra AS trials in place of LC trials, the last 8 LC trials that we analyzed could have been all 5 from Day 1 and the 3 from Day 2 (or 4 from Day 1 and 4 from Day 2, etc.). In sum, regardless of what day they fell on, the 8 trials analyzed were the last 8 trials performed by that child in that specific condition. Data from the 24-h retention probe trial was analyzed separately, and was not included in any LC or AS analyses.

A Wilcoxon signed-rank paired sample test, performed on the normalized number of correct versus incorrect choices within subject (and across the last 8 trials), was then performed to determine whether individual participants chose rewarded locations more often than non-rewarded locations for their first and their first three choices (statistical significance: $p<.05$ ).

The analyses of individual participants' performance revealed that the performance of the children in the AS condition differed depending on their age (see Results below). Based on these results, we separated the children into two different age groups ( $<42$ months and $>43$ months) in order to characterize the age-dependent learning process in the LC and AS conditions. Children $<42$ months completed 10.1 \pm 1.3 AS trials over the two days (range: $8-14 ; 19.7 \pm 1.7$ total LC and AS trials), whereas children $>43$ months completed $12.3 \pm 0.7$ AS trials (range: 11-14; $20.74 \pm 1.1$ total LC and AS trials). As described above, our decision to give children extra trials on Day 2 (e.g., 7 AS trials rather than 5) was based on a child's promising performance in the AS condition preceding the final trials (e.g., at least 3 of the last 5 trials with at least 2 of the 3 locations chosen correctly). Of the older children, 1 was given 1 extra trial, 21 were given 2, 2 were given 3 , and 3 given 4 . Of the younger children, only 3 children demonstrated probable proficiency: 1 was already clearly proficient in the AS condition prior to the final trial and thus was not given any more trials, 1 was given 2 extra trials, and 1 was given 4 extra trials (when statistical analyses were performed, all three of these children demonstrated statistical significance across the last 8 trials). Giving younger children that were not showing promising performance additional trials would not likely have changed their results, since these children tended to be discouraged, were losing motivation to continue the game ( 3 of 17 children did not finish all 10 trials on Day 2), and were not showing any evidence of discriminating the reward locations in the AS condition despite showing near perfect performance in the LC condition.

We performed two separate analyses of variance (ANOVAs), with age as a factor and trials as a repeated measure, including either the LC trials or the AS trials. $\mathrm{AChi}^{2}$ analysis of the number of boys and girls in each age group who discriminated the reward locations in the LC and/or AS conditions did not reveal any gender differences $\left(\mathrm{Chi}^{2}:<42\right.$ months $=0.275 ; p>0.50 ;>43$ months $=0.831 p>0.25$ ). We therefore grouped data from boys and girls for all analyses and presentation.

We also analyzed the performance of each child on the 24-h retention probe trial (the first trial of the second day conducted in the AS condition) in order to determine whether children could remember the locations of the rewards after $24 \mathrm{~h}$. We designated each of the children's first three choices as correct (C) or incorrect (I). We then calculated the probability to choose, by chance, either all three rewarded locations in the first three choices (i.e., CCC, $\left.(3 / 18)^{*}(2 / 17) *(1 / 16), p=.0012\right)$, two rewarded locations in the first two choices (i.e., CC, $\left.(3 / 18)^{*}(2 / 17), p=.0196\right)$, or two rewarded locations in the first three choices (i.e., CCI, CIC, ICC, $(0.01838+0.01838+0.01838), p=.0551)$.

\subsection{Results}

\subsubsection{Individual and group performance}

We first evaluated each individual child's ability to discriminate the reward locations in the LC condition (i.e., when red cups marked those locations) and in the AS condition (i.e., in the absence 
of red cups), by analyzing which three locations children searched first upon entering the arena. The results for all children are shown in Table 1 ('No': participant did not exhibit statistical evidence that he/she discriminated the reward locations in that specific condition; 'Yes': participant exhibited statistical evidence that he/she discriminated the reward locations; Wilcoxon signed-rank test; correct versus incorrect, all $p<.05$ ), and summarized graphically in Fig. 2. Our analyses showed that all of the 25-61-month-old children tested demonstrated that they could discriminate the reward locations in the LC condition.

In contrast, children's performance in the AS condition was dependent on their age (Table 1). An agegroup comparison (children $<42$ months $(n=17)$ versus children $>43$ months $(n=27)$ ) confirmed that the proportion of children who discriminated the three reward locations in the AS condition differed between age groups $\left(\mathrm{Chi}^{2}=28.719, p<.001\right)$. Of the 17 children $<42$ months tested (Table 1 and Fig. 2 ), only three $(18 \%$; $35.5,37.4$ and 38.4 months of age) demonstrated that they were capable of discriminating the reward locations, whereas 14 (82\%) could not. In contrast, 26 of 27 (96\%) children >43 months demonstrated that they could discriminate the rewarded locations from the never-rewarded locations.

To ensure that our criteria for defining success were not too strict (e.g., some children might demonstrate the ability to discriminate one of the three reward locations reliably, but not necessarily all three), we also analyzed the first location that children searched in the AS condition. As shown in Table 1 , the results of only one child ( 54.7 months) differed between the analyses of the first and first three visited locations. Counter-intuitively, he did not exhibit statistical evidence of discrimination based on his first choice $(p=.084)$, but he did discriminate the reward locations based on the analysis of the first three visited locations. Detailed analysis of his behavior showed that during his last eight trials in the AS condition, he made a total of three errors when searching the first location (perhaps exhibiting a lack of inhibition or disorientation upon entering the arena), but then chose rewarded locations for either the next choice (on 1 trial), or the next two choices ( 2 trials) on those three trials, thus explaining the incongruity between his results for the first and first three visited locations. For all the other children, the results of both analyses were consistent.

\subsubsection{Learning curve}

Fig. 3 presents the trial-by-trial performance of the two groups of children for all five trials on Day 1, and the first three trials on Day 2 in the LC (Fig. 3A) and AS (Fig. 3B) conditions. Note that since these data represent the learning curve (children's first 8 trials), they differ from the data presented in Fig. 2 (children's last 8 trials). Note also that the 24-h retention probe trial, the first trial of Day 2, was analyzed separately and is not included in this graph; its results are presented in Section 2.2.3 below. Six children, five subjects in the $<42$ months group (including the three youngest subjects $<32$ months of

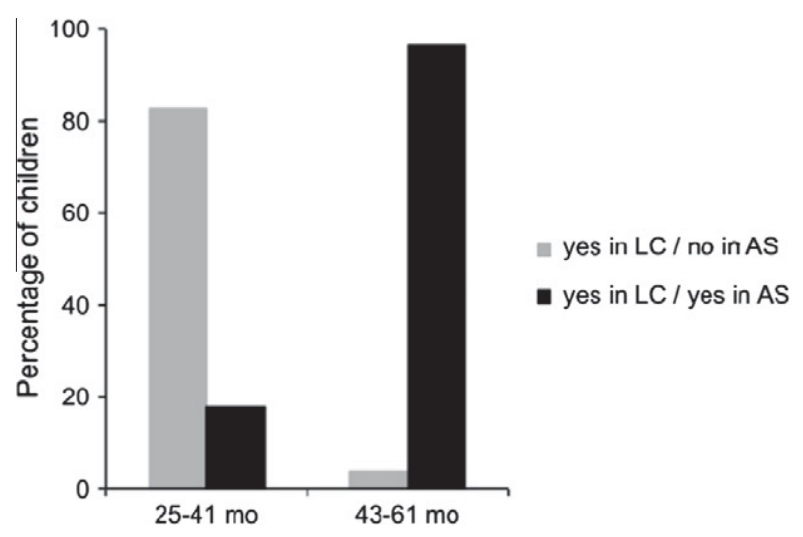

Fig. 2. Performance of 25-61-month-old children in Experiment 1 with three reward locations among 18 possible locations. LC; local cue condition; AS: allocentric spatial condition. Note: All children discriminated the reward locations in the LC condition. 

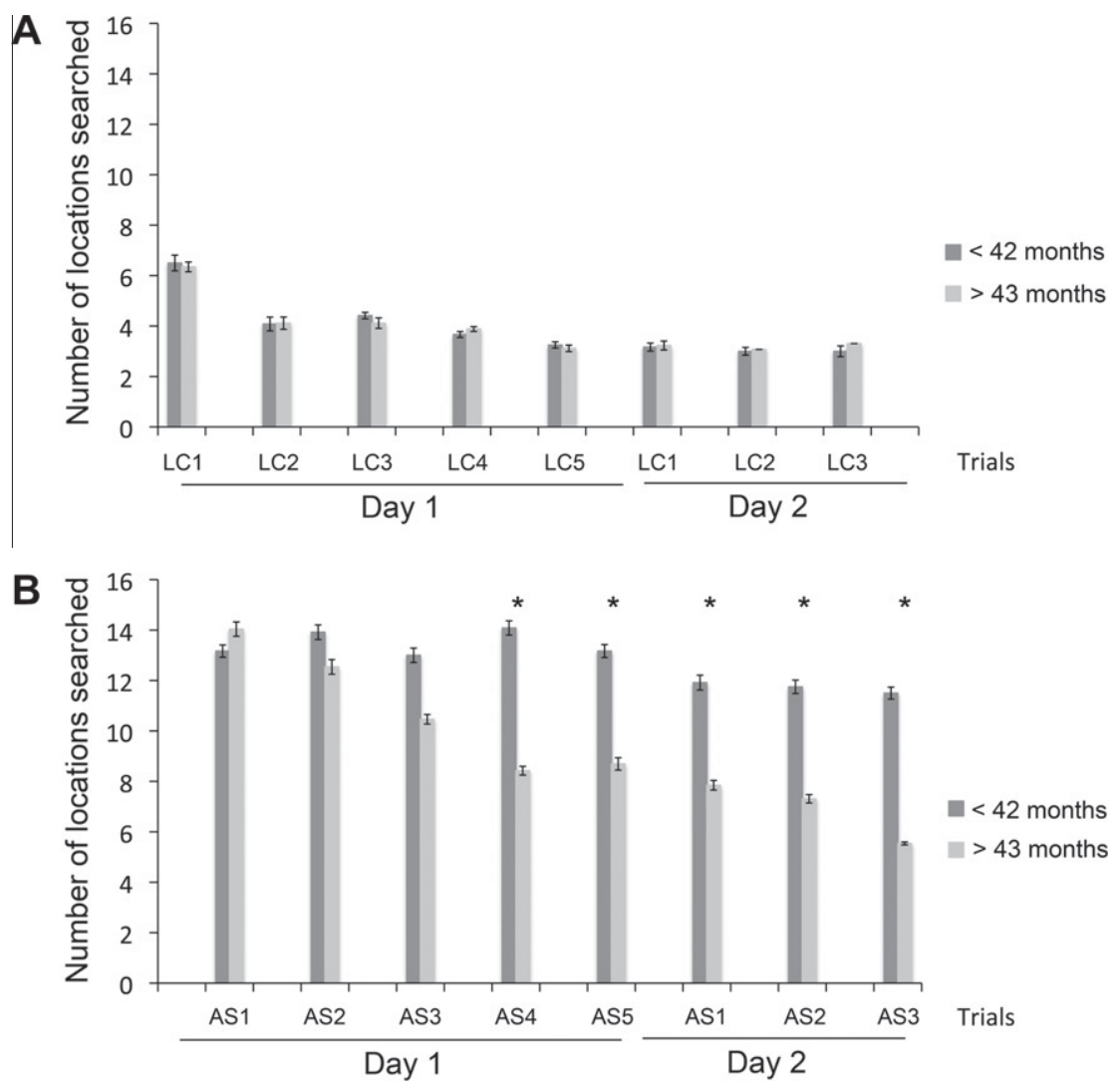

Fig. 3. Learning curves of children $<42$ - and $>43$-months-of-age in Experiment 1 , with three reward locations among 18 potential locations; number of locations searched to find the three rewards. (A) Local cue condition (LC). (B) Allocentric spatial condition (AS). Asterisks $\left({ }^{*}\right)$ denote statistical differences $(p<.05)$ between the two groups on that individual trial.

age) and one subject in the $>43$ months group (61-months-old), did not search on their own during the first one to four trials of Day 1 (see Section 2.1.3) and were thus not included in this analysis. They are identified by an underline in Table 1 .

We compared the number of locations that children $<42$ months and $>43$ months visited in order to find the three rewards in the LC condition (Fig. 3A), and found a difference between trials $(F(7,252)=13.408, p<.0001)$, but no difference between groups $(F(1,36)=.001, p=.977)$ nor any interaction between groups and trials $(F(7,252)=.108, p=.998)$. Thus, both groups decreased the total number of locations visited after the first trial ( $<42$ months, $F(7,77)=16.619, p<.0001 ;>43$ months, $F(7,175)=30.340, p<.0001)$ and stabilized the number of searched locations by the fifth trial of Day 1 (Fig. 3A), visiting almost exclusively the reward locations. There was no significant difference between the two age groups on any individual trial in this condition.

Comparing the number of locations that children searched to find the three rewards in the AS condition (Fig. 3B) revealed differences between groups $(F(1,36)=13.380, p=.001$ ), between trials $(F(7,252)=7.104, p<.0001)$ and an interaction between groups and trials $(F(7,252)=3.041$, $p=.004)$. Children $>43$ months gradually improved their performance on each successive trial $(F(7,175)=206.646, p<.0001)$, whereas those $<42$ months $\operatorname{did}$ not $(F(7,77)=1.088, p=.379)$. Children $>43$ months performed significantly better than children $<42$ months on Trials 4 and 5 of Day 1 , and on Trials 1,2 , and 3 of Day 2 (all $p<.05$ ). 


\subsubsection{Retention probe trial}

In order to test children's long-term $(\geqslant 24 \mathrm{~h})$ memory of the reward locations, the first trial of the second day was an AS trial in which no local cues marked these locations. We analyzed each child's responses independently to determine how many rewarded locations they searched among the first three visited locations. In order to conclude whether that child "knew" where the rewards were hidden, we calculated the probability of choosing all three of the first three locations correctly (i.e., CCC, $p=.0012$ ), the first two locations correctly (i.e., CC, $p=.0196$ ) or any two of the first three locations correctly (i.e., CCI, CIC or ICC, $p=.0551$ ). Although choosing two of the first three locations correctly does not reach the standard threshold of probability at $p<.05$, we believe that the performance of

Table 2

Performance of individual children in the 24-h retention probe trial: First three locations searched.

\begin{tabular}{|c|c|c|c|}
\hline Age (mo) & $\mathrm{M} / \mathrm{F}$ & Correct/incorrect & Probability \\
\hline $25.8^{\mathrm{a}}$ & M & IIC & \\
\hline$\overline{29.4}$ & M & $\mathrm{N} / \mathrm{A}$ & \\
\hline$\underline{31.5}$ & $\mathrm{~F}$ & CII & \\
\hline$\overline{34.2}$ & $\mathrm{~F}$ & CII & \\
\hline 34.5 & $\mathrm{~F}$ & CII & \\
\hline 34.9 & M & III & \\
\hline 35.1 & $\mathrm{~F}$ & III & \\
\hline 35.5 & $\mathrm{~F}$ & IIC & \\
\hline 36.3 & M & $\mathrm{ICI}$ & \\
\hline $36.4^{\mathrm{a}}$ & M & III & \\
\hline $36.4^{\mathrm{a}}$ & M & III & \\
\hline $36.7^{\mathrm{a}}$ & $\mathrm{F}$ & III & \\
\hline 37.4 & M & CII & \\
\hline 38.4 & M & $\mathrm{CIC}$ & $p=.0551$ \\
\hline 38.9 & $\mathrm{~F}$ & III & \\
\hline 39.5 & $\mathrm{~F}$ & III & \\
\hline 41.8 & M & CII & \\
\hline 43.7 & $\mathrm{~F}$ & $\mathrm{CCC}$ & $p=.0012$ \\
\hline 46.2 & M & CII & \\
\hline 46.3 & M & III & \\
\hline 46.3 & $\mathrm{~F}$ & III & \\
\hline 46.4 & $\mathrm{M}$ & III & \\
\hline 46.5 & $\mathrm{~F}$ & CII & \\
\hline 47.2 & M & $\mathrm{CCI}$ & $p=.0196$ \\
\hline 47.4 & $\mathrm{~F}$ & III & \\
\hline 48.0 & $\mathrm{~F}$ & CII & \\
\hline $48.4^{\mathrm{a}}$ & M & $\mathrm{CIC}$ & $p=.0551$ \\
\hline $50.4^{\mathrm{a}}$ & $\mathrm{F}$ & CII & \\
\hline $50.8^{\mathrm{a}}$ & $\mathrm{F}$ & $\mathrm{CCC}$ & $p=.0012$ \\
\hline 50.9 & $\mathrm{~F}$ & $\mathrm{CIC}$ & $p=.0551$ \\
\hline $52.3^{\mathrm{a}}$ & $\mathrm{M}$ & $\mathrm{CCC}$ & $p=.0012$ \\
\hline $54.1^{\mathrm{a}}$ & M & CCC & $p=.0012$ \\
\hline $54.7^{\mathrm{a}}$ & M & $\mathrm{ICI}$ & \\
\hline 54.9 & $\mathrm{~F}$ & CII & \\
\hline 55.3 & F & $\mathrm{CCC}$ & $p=.0012$ \\
\hline 56.4 & $\mathrm{~F}$ & CII & \\
\hline $56.5^{\mathrm{a}}$ & M & III & \\
\hline $57.2^{\mathrm{a}}$ & M & CII & \\
\hline 59.3 & $\mathrm{~F}$ & CII & \\
\hline $59.8^{\mathrm{a}}$ & $\mathrm{M}$ & $\mathrm{CCI}$ & $p=.0196$ \\
\hline $60.6^{\mathrm{a}}$ & M & IIC & \\
\hline 61.0 & M & IIC & \\
\hline$\underline{61.5}^{\mathrm{a}}$ & M & $\mathrm{CCC}$ & $p=.0012$ \\
\hline $61.8^{\mathrm{a}}$ & M & $\mathrm{ICI}$ & \\
\hline
\end{tabular}

UNDERLINE: results not included in learning curve analysis (See Section 2.2.2). a Participated in pilot experiment 9 months prior. 
these children is nonetheless noteworthy, and thus we present their results here (Table 2). Of the 17 children $<42$ months, only one made two correct choices within the first three choices $(p=.0551)$, thus demonstrating some memory for the reward locations after a 24-h interval. In contrast, of the 27 children $>43$ months, six chose all three of the first three locations correctly (CCC; $p=.0012$ ), and two chose the first two locations correctly before making an error (CC; $p=.0196$ ), making a total of eight children that demonstrated statistically that they remembered the reward locations after a 24-h interval. An additional two children chose two locations correctly within the first three choices $(p=.0551)$.

\subsection{Discussion - Experiment 1}

Experiment 1 showed that children older than 43 months of age were capable of learning and remembering an allocentric, spatial representation of the environment to identify reward locations in a real-world spatial memory task. In contrast, as a group, children younger than 42 months of age were not capable of solving this task. The successful performance of the younger children ( $<42$ months) in the LC condition demonstrated that they were motivated to participate and understood the overall goal of the task (Fig. 3a; their performance in this condition was indistinguishable from that of the older children). Nevertheless, in the AS condition, children $<42$ months of age did not discriminate the same spatial locations that they were directly navigating to and finding rewards at on every other trial in the $\mathrm{LC}$ condition $\left(\mathrm{LC}_{1}, \mathrm{AS}_{1}, \mathrm{LC}_{2}, \mathrm{AS}_{2}, \ldots, \mathrm{LC}_{10}, \mathrm{AS}_{10}\right)$.

Previous studies reported that, in the first year of life, infants often respond in an egocentric manner when orienting (Acredolo, 1978; Acredolo \& Evans, 1980; Bremner \& Bryant, 1977; Cornell \& Heth, 1979; Rieser, 1979). Nevertheless, between 6 and 12 months, infants begin to demonstrate that they are capable of orienting by using visual guidance strategies employing coincident or adjacent visual cues or landmarks (Acredolo, 1978; Acredolo \& Evans, 1980; Bremner, 1978a,b; Bushnell, McKenzie, Lawrence, \& Connell, 1995; Tyler \& McKenzie, 1990). Between 6 and 12 months of age infants also begin showing that they can orient using path integration/dead reckoning (Acredolo, 1978; Acredolo, Adams, \& Goodwyn, 1984; Rieser \& Heiman, 1982), and, for example, can use closely related landmarks to visually identify a goal location after rotation and translation (Lew, Bremner, \& Lefkovitch, 2000). Finally, the earliest suggestive evidence for the use of distal, non-aligned visual cues to orient in space, i.e., allocentric spatial capacities, is around 22 months of age (Newcombe et al., 1998).

In contrast, our experiment suggests that children under 42 months of age were not able to discriminate goal locations using an allocentric spatial representation of the surrounding environment. Our findings thus differ substantially from those of Newcombe, which suggested that children as young as 22 months benefited from the availability of distal visual cues in order to improve their search for a toy hidden in a sandbox (Newcombe et al., 1998). Such differences might be due to the complexity of the environment, as we tested children in a bare environment with numerous decoy locations. In order to address this question, and to further investigate the allocentric spatial capacities of children under 42 months, we tested children in a simplified version of the search task that included only one reward location among four potential locations distributed in the same open-field environment.

\section{Experiment 2}

\subsection{Method}

The overall design of Experiment 2 was the same as for Experiment 1, including how participants were recruited, the testing rooms, the arena and the majority of the procedures. We therefore only describe the aspects of Experiment 2 that differed from those of Experiment 1.

\subsubsection{Participants}

Participants were 38 children (17 males, age range 18.9-32.0 months; 21 females, age range 17.939.6 months). Nine children were tested in the canton of Vaud, and 29 in the canton of Fribourg. We found no differences in the behavior or performance of the children tested in these two different loca- 
tions, and therefore all of the data gathered at these two sites were grouped for analysis and presentation. Three of the 38 children (denoted by an asterisk in Table 1) had participated nine months earlier in a pilot study that investigated their ability to solve a similar spatial task (with six regularlyarranged goal locations amongst 18 potentially rewarded locations; none of the goal locations were the same as that used in this study).

\subsubsection{Testing facility}

The testing rooms and arenas were identical to those described for Experiment 1, except that four white paper plates were symmetrically arranged, with one plate and inverted cup located at each of the four cardinal points within the arena (Fig. 4). Only one of the four locations was rewarded (either location 2 or 4), and, as in Experiment 1, each potential location in the arena was uniquely defined by its relations with distal visual objects in the testing room.

\subsubsection{Testing procedure}

The procedures for Experiment 2 were the same as those described for Experiment 1. For each child, only one location was rewarded; half of the children were tested with location 2 and the other half of the children were tested with location 4 (Fig. 4; locations 1 and 3 were never rewarded). The reward location remained constant for each child for all of the trials on the two days of testing. After searching a location, children were given verbal feedback and encouragement such as "Yeah! Always here! This is the good plate!" or "Oh no. Never here. This is the bad plate." Or, sometimes just "Yes, yes," or "No, no" while pointing at the location a child had just searched.

\subsubsection{Data analysis}

To assess the children's ability to discriminate the rewarded location from the three never-rewarded locations in the LC and AS conditions, we analyzed the first location that each individual child searched during each trial, and coded that choice as correct or incorrect. We normalized the number of choices of a particular type based on the probability to make that choice: The number of choices of the rewarded (correct) location was divided by one and the number of choices of never-rewarded (incorrect) locations was divided by three. As for Experiment 1, only the last eight trials in each condition were used for statistical analyses. A Wilcoxon signed-rank paired sample test, performed on the nor-

A

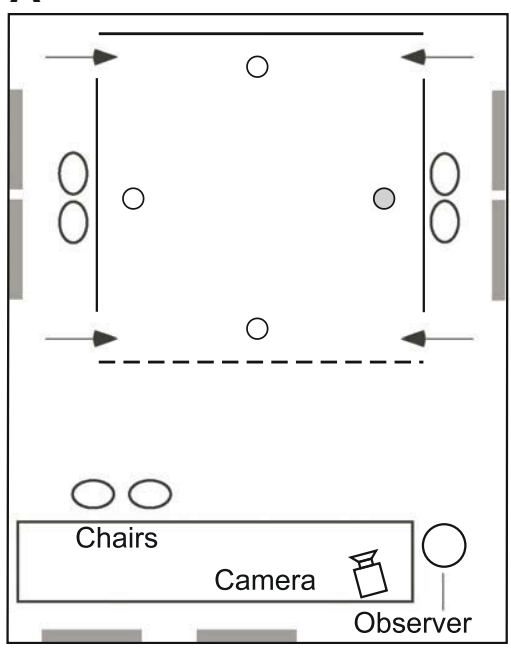

B

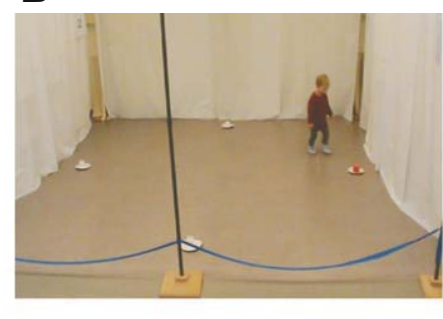

D

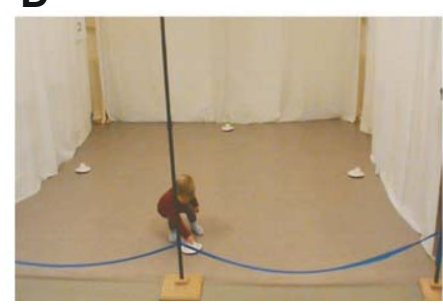

C

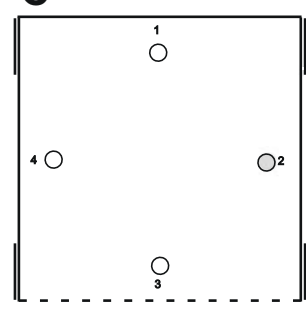

E

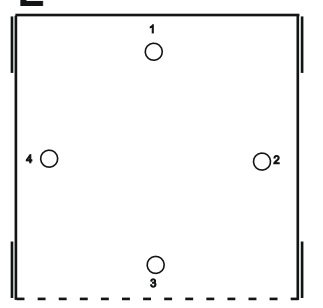

Fig. 4. Experimental setup. (A) Schematic of the testing room $(7 \mathrm{~m} \times 6 \mathrm{~m})$ and the arena $(4 \mathrm{~m} \times 4 \mathrm{~m})$, including tables, chairs, and posters (gray rectangles). (B) Picture of a participant in the arena in the LC condition. (C) Schematic of the LC condition. (D) Picture of a participant in the arena in the AS condition. (E) Schematic of the AS condition. 
malized number of correct versus incorrect choices within subject (and across the last 8 trials), was performed to determine whether each participant discriminated the reward location (with statistical significance designated as $p<.05$ ).

The analyses of individual participants' performance revealed that the performance of the children in the allocentric spatial condition differed depending on their age (see Section 3.2 below). Based on these results, we separated the children into two different age groups ( $<24$ months and $>25$ months), in order to evaluate the age-dependent learning process in the LC and AS conditions. As in Experiment 1 , children who demonstrated probable proficiency in the AS condition could be given extra AS trials at the end of Day 2. Children <24 months completed 11.2 \pm 1.1 AS trials over the two days (range 10$13 ; 21.0 \pm 1.2$ total trials), whereas children $>25$ months completed $11.4 \pm 1.4$ AS trials (range 10-14; $20.7 \pm 1.1$ total trials). As before, our decision to give children extra trials on Day 2 was based on their promising performance in the AS condition preceding the final trials (e.g., at least 3 of the last 5 trials with the rewarded location chosen correctly). Of the younger children, 12/19 were given extra AS trials (from 1 to 3 ). Of the older children, 11/19 were given extra AS trials (from 1 to 4 ).

We performed two separate analyses of variance (ANOVAs), with age as a factor and trials as a repeated measure, including either only the LC trials or the AS trials. A Chi ${ }^{2}$ analysis of the number of boys and girls in each age group who discriminated the reward locations in the LC and/or AS conditions did not reveal any gender differences $\left(\mathrm{Chi}^{2}:<24\right.$ months $=.014, p>0.90 ;>25$ months $=.019$, $p>0.75)$. We therefore grouped data from boys and girls for all analyses and presentation.

We also analyzed the performance of each child on the 24-h retention probe trial (the first trial of the second day conducted in the AS condition) in order to determine whether children could remember the reward location after a 24-h interval. We designated each child's first choice as correct (C) or incorrect (I). Since the probability of choosing the correct location by chance (i.e., 25\%) was too high to demonstrate statistically whether children remembered the reward location $24 \mathrm{~h}$ later, we present the number of children in each age group that searched the correct location first in the $24 \mathrm{~h}$ retention probe trial. We performed a $\mathrm{Chi}^{2}$ analysis to evaluate potential differences in group performance.

\subsection{Results}

\subsubsection{Individual and group performance}

We evaluated the children's ability to discriminate the reward location in the LC and AS conditions by analyzing which location children searched first upon entering the arena. Of the 19 children $<24$ months that we tested, eleven (58\%) demonstrated that they were capable of discriminating the reward location in the presence of the local cue (Fig. 5 and Table 3). However, performance in this

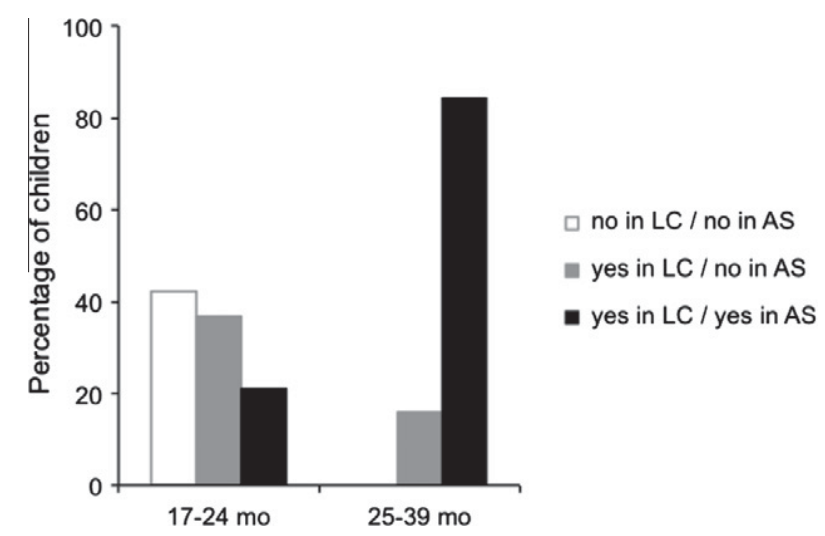

Fig. 5. Performance of 17-39-month-old children in Experiment 2 with one reward location among four possible locations. LC: local cue condition; AS: allocentric spatial condition. Note: All children $>25$ months discriminated the reward location in the LC condition, so there are no results in the "no LC/ no AS" category. 
Table 3

Performance of individual children in Experiment 2 with one reward location among four possible locations.

\begin{tabular}{|c|c|c|c|c|c|}
\hline \multirow{2}{*}{\multicolumn{2}{|c|}{ Participants }} & \multicolumn{4}{|c|}{ Location discriminated in: } \\
\hline & & \multicolumn{2}{|c|}{ Local cue condition } & \multicolumn{2}{|c|}{ Allocentric spatial condition } \\
\hline Age (mo) & $\mathrm{M} / \mathrm{F}$ & No & Yes & No & Yes \\
\hline 17.9 & $\mathrm{~F}$ & $\mathrm{X}$ & & $\mathrm{X}$ & \\
\hline 18.0 & $\mathrm{~F}$ & & $\mathrm{X}$ & $\mathrm{X}$ & \\
\hline 18.8 & $\mathrm{~F}$ & & $\mathrm{X}$ & $\mathrm{X}$ & \\
\hline 18.9 & M & $\mathrm{X}$ & & $\mathrm{X}$ & \\
\hline 19.5 & M & $\mathrm{x}$ & & $\mathrm{X}$ & \\
\hline 19.6 & $\mathrm{~F}$ & $\mathrm{X}$ & & $\mathrm{X}$ & \\
\hline$\overline{19.7}$ & M & $\mathrm{X}$ & & $\mathrm{X}$ & \\
\hline 19.8 & $\mathrm{~F}$ & & $\mathrm{X}$ & & $\mathrm{X}$ \\
\hline 19.9 & M & $\mathrm{X}$ & & $\mathrm{X}$ & \\
\hline 20.1 & $\mathrm{~F}$ & & $X$ & X & \\
\hline 20.2 & M & & $\mathrm{X}$ & & $\mathrm{X}$ \\
\hline 22.0 & M & & $\mathrm{X}$ & $\mathrm{X}$ & \\
\hline 22.1 & M & & $\mathrm{X}$ & $\mathrm{X}$ & \\
\hline 22.4 & M & & $\mathrm{X}$ & $\mathrm{X}$ & \\
\hline 22.7 & M & & $\mathrm{X}$ & & $\mathrm{X}$ \\
\hline 22.7 & M & $\mathrm{X}$ & & $X$ & \\
\hline 22.8 & $\mathrm{~F}$ & & $X$ & & $X$ \\
\hline 23.0 & $\mathrm{~F}$ & & $X$ & $X$ & \\
\hline 23.4 & $\mathrm{~F}$ & $X$ & & $X$ & \\
\hline 25.4 & M & & $X$ & & $X$ \\
\hline 26.0 & $\mathrm{~F}$ & & $X$ & & $X$ \\
\hline 26.5 & $\mathrm{~F}$ & & $X$ & & $X$ \\
\hline$\overline{27.0^{\mathrm{a}}}$ & $\mathrm{M}$ & & $X$ & & $X$ \\
\hline 27.1 & $\mathrm{~F}$ & & $X$ & & $x$ \\
\hline 27.7 & $\mathrm{M}$ & & $X$ & $\mathrm{X}$ & \\
\hline$\overline{27.9}$ & M & & $X$ & & $X$ \\
\hline 28.0 & $\mathrm{~F}$ & & $X$ & $X$ & \\
\hline 28.3 & $\mathrm{~F}$ & & $X$ & & $X$ \\
\hline 30.7 & M & & $X$ & & $X$ \\
\hline 31.1 & M & & $X$ & & $X$ \\
\hline 31.6 & $\mathrm{~F}$ & & $X$ & & $X$ \\
\hline 32.0 & M & & $X$ & & $X$ \\
\hline $32.1^{\mathrm{a}}$ & $\mathrm{F}$ & & $X$ & & $\mathrm{X}$ \\
\hline 32.2 & $\mathrm{~F}$ & & $X$ & $X$ & \\
\hline 35.2 & $\mathrm{~F}$ & & $X$ & & $X$ \\
\hline 35.6 & $\mathrm{~F}$ & & $\mathrm{X}$ & & $\mathrm{X}$ \\
\hline 35.8 & $\mathrm{~F}$ & & $X$ & & $\mathrm{X}$ \\
\hline $39.6^{\mathrm{a}}$ & $\mathrm{F}$ & & $X$ & & $X$ \\
\hline
\end{tabular}

UNDERLINE: results not included in learning curve analysis (Section 2.2.2).

a Participated in pilot experiment 9 months prior.

condition of the task was also dependent on age within this age group. For those children $<20$ months, only 3 of 9 (33\%) discriminated the reward location in the LC condition, whereas for those children $\geqslant 20$ months, 8 of 10 (80\%) did so (Table 3 ). Among those eleven children who reliably used the local cue to identify the reward location, seven (37\% of 19) were incapable of discriminating this same location in the absence of the local cue, and only four (21\% of 19; aged 19.8, 20.2, 22.7 and 22.8 months of age) demonstrated that they could also discriminate the reward location in the AS condition.

In contrast, all 19 children $>25$ months demonstrated that they could discriminate the reward location in the LC condition. Moreover, 16 of 19 children $>25$ months (84\%) demonstrated that they were capable of discriminating the reward location in the AS condition. The three children who failed to discriminate the reward location in the AS condition were 27.7, 28.0 and 32.3 months of age. A statistical analysis confirmed that the proportion of children who discriminated the reward location in the AS 
condition differed between age groups ( $<24$ months (4 of 19) versus $>25$ months (16 of 19): $\left.\mathrm{Chi}^{2}=15.200, p<.001\right)$.

\subsubsection{Learning curve}

Fig. 6 presents the trial-by-trial performance of the two groups of children for all five trials on Day 1, and the first three trials on Day 2 in the LC (Fig. 6A) and AS (Fig. 6B) conditions (note that the 24-h retention probe trial, the first trial of Day 2, was analyzed separately and is presented in Section 3.2.3 below). Six children (four participants in the $<24$ months group, and two participants, 26.5- and 27.7months-old, in the $>25$ months group) did not search on their own during the first one to four trials of Day 1 (see Section 2.1.3) and thus were not included in this analysis. They are identified by an underline in Table 3.

We compared the number of locations that children $<24$ months and $>25$ months searched in order to find the reward in the LC condition (Fig. 6A). We found a difference between trials $(F(7,210)=3.438$, $p<.002)$ and between groups $(F(1,30)=7.305, p=.011)$, but no interaction between trials and groups $(F(7,210)=.404, p=.575)$. Post-hoc analyses performed between trials for each group of children independently showed that this result arose from the fact that whereas the younger children decreased the total number of cups that they searched after the first trial, because the older children were already searching very few cups, they did not ( $<24$ months, $F(7,98)=2.623, p=.016$; $>25$ months,
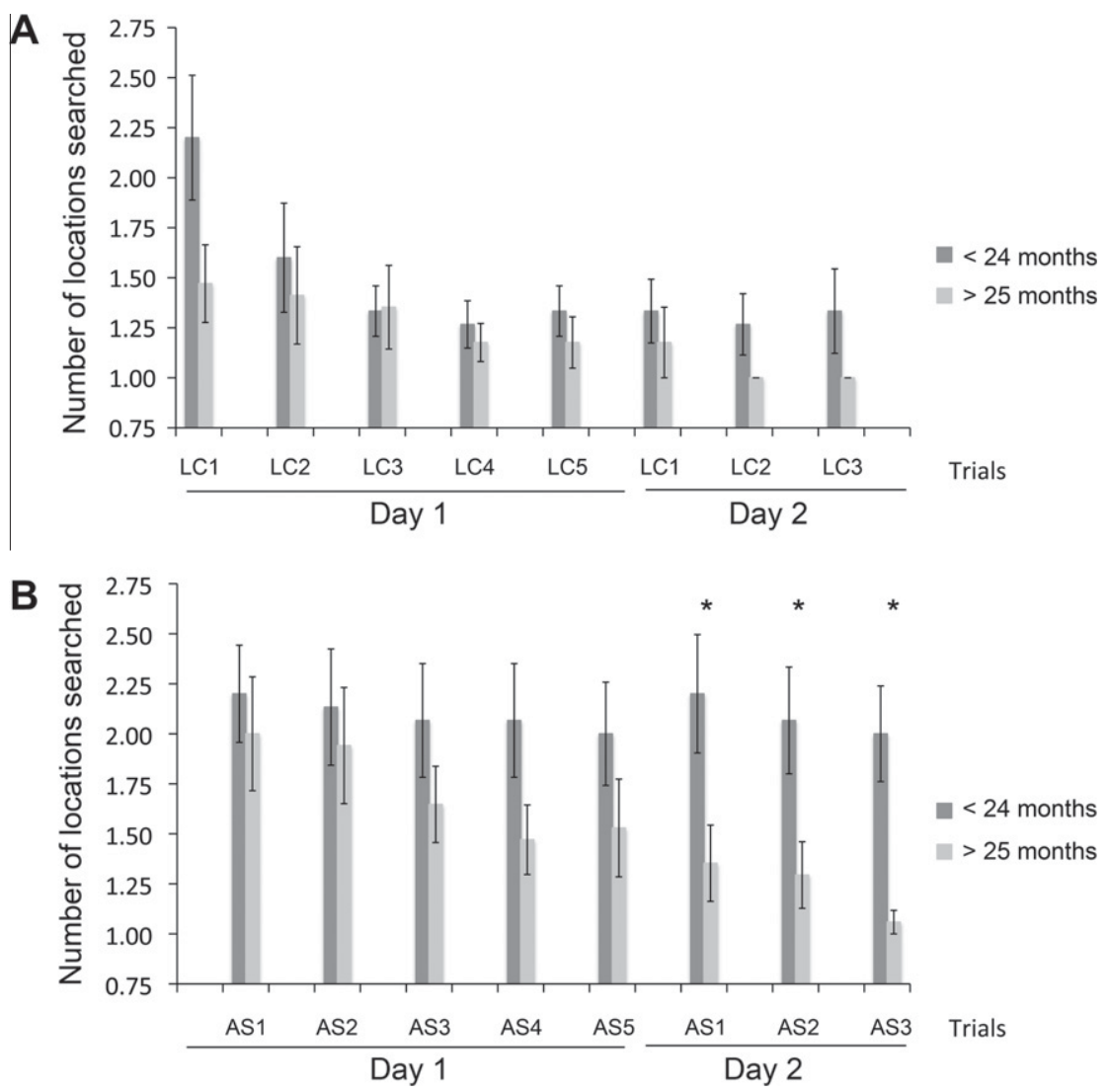

Fig. 6. Learning curves of children $<24$ - and $>25$-months-of-age in Experiment 2, with one reward location among four potential locations: Number of locations searched to find the reward. (A) Local cue condition (LC). (B) Allocentric spatial condition (AS); Asterisks $\left({ }^{*}\right)$ denote statistically significant differences $(p<.05)$ between groups on that individual trial. 
$F(7,112)=1.258, p=.278)$. Despite an overall group difference, there was no significant difference between the two age groups on individual trials in this condition.

The analysis of the number of locations that children searched to find the reward in the AS condition (Fig. 6B) revealed a difference between groups $(F(1,30)=10.6, p=.003)$, but not between trials $(F(7,210)=1.377, p<.216)$, nor any interaction between groups and trials $(F(7,210)=0.819$ $p=.573$ ). Analyses performed for each group independently showed that children $<24$ months did not improve their performance with successive trials $(F(7,98)=.098, p=.998)$, whereas those $>25$ months did $(F(7,112)=2.725, p=.012)$. Children $>25$ months performed significantly better than children $<24$ months on Trials 1,2 , and 3 of Day 2 (all $p<.05$ ).

\subsubsection{Retention probe trial}

In order to test children's long-term $(\geqslant 24 \mathrm{~h}$ ) memory for the reward location, the first trial of the second day was an AS trial in which no local cue marked the reward location. Because there were only four potential locations, however, the probability of choosing the reward location by chance was $25 \%$, thus making this measure inappropriate for evaluating statistically whether individual children remembered the reward location after a 24-h delay. Instead, we compared how many children in the two age groups ( $<24$ months and $>25$ months) chose the reward location first. A Chi ${ }^{2}$ analysis failed to reveal a statistically significant difference in the number of children $<24$ months (10 of 19) and those $>25$ months ( 14 of 19 ) who chose the reward location first after $24 \mathrm{~h}\left(\mathrm{Chi}^{2}=1.810, p>.10\right)$.

\subsection{Discussion - Experiment 2}

Experiment 2 showed that children older than 25 months of age were capable of forming and remembering an allocentric spatial representation of the environment to identify a single reward location in a real-world memory task, whereas children under 24 months of age did not reliably exhibit such capacity. Indeed, among 19 children under 24 months of age, only four children $(19.8,20.2$, 22.7, 22.8 months of age) exhibited this capacity. Thus, in contrast with the results of Experiment 1, the results of Experiment 2 are in agreement with those of a previous study (Newcombe et al., 1998) suggesting that children begin using distal visual cues to identify locations around 22 months of age. Considering the evidence from these two experiments, a very compelling argument for the emergence of basic allocentric capacities in children between 20 and 24 months of age can be made.

Although the specifics of Newcombe's task and our task differ significantly, their results are remarkably similar. In Newcombe's study, children watched while a small plastic toy was buried in a sandbox. Half of the children were tested with access to distal visual cues in the room during hiding and retrieval, whereas for the other half an opaque curtain surrounding the experimental apparatus blocked their access to distal visual cues. After being asked to turn around and look briefly at their parent who was located behind them (in order to break eye contact with the hiding location), children were guided to the opposite side of the sandbox where they were asked to search for the toy under the smooth sand surface. Children older than 22 months of age benefited from the presence of the distal visual cues to increase search accuracy, whereas younger children did not (Newcombe et al., 1998). As described previously, the fact that children experienced a different viewpoint ( $180^{\circ}$ opposite) when retrieving the hidden toy as compared to when the toy was hidden, argues against the possibility that children could use a visual guidance strategy (i.e., by either associating the reward location with a nearby object, or by visually-aligning the reward location with a distal object in the environment). In our task, children were constantly moving within and on the adjacent outsides of the arena, and were required to wait out of eye contact of the goal location for one minute, during which time they were kept occupied, before re-entering the arena from a position that was different from that through which they had entered and exited on the immediately preceding trial. In addition, although in our task the exact goal location was "signaled" by the presence of a plate and cup limiting the need for a precision search (i.e., in contrast to a smooth sand surface), children were confronted by the presence of four potential goal locations upon entering the arena. Regardless of such differences, we found that $84 \%$ of children older than 25 months discriminated the reward location in the absence of local cues marking that location. In sum, our study confirms those findings suggested by Newcombe et al. (1998), 
and demonstrates that basic allocentric spatial memory abilities emerge after 20 months of age and are consistently present after two years of age in children.

\section{General discussion}

\subsection{Task specificity}

Because the importance of distinguishing between allocentric, egocentric, visual guidance and path integration strategies is often overlooked in spatial memory investigations (see Banta Lavenex \& Lavenex, 2009, 2010, for discussion), it is worth explaining why it is critical to control for these latter three non-allocentric strategies when studying allocentric spatial memory, and specifically how our paradigm precludes the use of egocentric and visual guidance strategies, and why path integration alone is insufficient to solve our task.

Egocentric spatial strategies are based on identifying a goal location in relation only to a subject's body (e.g., "turn left") or via a sequence of body-centered actions (e.g., "turn right, take two steps, turn left"). Humans and other animals employ egocentric strategies regularly in a variety of spatial environments. However, since egocentric capacities are not dependent on the integrity of the hippocampal formation (Eichenbaum et al., 1990; Rogers \& Kesner, 2006; Weniger \& Irle, 2006; Weniger et al., 2009), it is critical to prevent subjects from using egocentric strategies when using allocentric spatial capacities as an assay for hippocampal function (Banta Lavenex \& Lavenex, 2009). In our paradigm, the use of four different entrance points and multiple potential reward locations precludes children from using egocentric strategies. For example, a child using an egocentric strategy to identify the reward locations, such as "the first cup on my right," would be correct only one out of four times (the child would be consistently correct when entering from one door, but consistently incorrect when entering from the three other doors). Moreover, subjects cannot encode four different egocentric rules for how to find the reward locations from each entrance point since for this strategy to work, the subject must encode the entrance location in a framework that is independent of the position of the subject's body, i.e., in an allocentric frame of reference. In contrast, defining the reward location as "the cup that is in front of me when the distal visual cues are on my right" is a form of allocentric coding: the location and orientation of the searcher is defined in relation to distal objects in the environment, and then the location of the reward is defined in relation to the searcher. Indeed, as the child enters the arena, sometimes the distal objects in the environment are on her right, sometimes on her left, sometimes behind her, sometimes in front of her. She must orient her search to a location defined with respect to distal environmental objects. Nevertheless, one could imagine that in the absence of allocentric capacities (e.g., in very young children or brain-damaged patients), a strategy may be adopted where the subject goes to the center of the arena, turns until the open side of the arena is on her left, and then chooses the cup directly in front of them, which would constitute an egocentric strategy. Although this strategy may be successful in our 4-location task (although see below why we believe it is not), it is not possible in the 18-location task (with 3 rewarded locations, none of which are found directly on the cardinal axes). Importantly, however, we have never once seen any child employ a strategy of going to the center of, or any other place within, the arena and then systematically attempting to identify the rewarded location(s). Instead, children enter the arena and walk directly to locations that they would like to search, whether they are correct or not (i.e., we did not see a difference in search strategy between children who succeeded and those who did not).

When using a visual guidance strategy (a.k.a. cue learning or beaconing), subjects rely on salient visual cues coincident with, or visually aligned with, the goal location (Gallistel, 1990), thus successfully identifying goal locations using simple, non-spatial associations. In small testing areas, these visual cues may be items such as doors, windows, chairs, and wall heaters, located adjacent to or directly behind the goal, thus allowing subjects to make the visual or verbal association that the reward is "by the radiator" or "in line with the window". In larger testing areas, these landmarks may be items such as trees, play structures, parking areas, buildings or mountains. Our LC condition provided children with a visual guidance solution: a red cup was present at the rewarded location. In contrast, in the AS condition all goal and decoy locations were identical, a white paper plate covered 
by an inverted white plastic cup, thus providing no coincident distinguishing visual cues. Moreover, because our arena is enclosed on three sides by opaque curtains, we also eliminate visually-aligned guidance cues. For example, in our 4-location task, the visual appearance of three of the four potential reward locations is identical in that each is situated $50 \mathrm{~cm}$ in front of an opaque curtain (the 4th location, in front of the open side of the arena, is never used as a rewarded location), thus providing no distinct distal visual cues with which the goal location can be aligned or visually bound. In our 18location task, nearly every location has overlapping visual characteristics with another location in the arena, again providing no distinctive visual guidance cues. Thus, our paradigm precludes children from using visual guidance strategies.

Snapshot or template matching is a type of visual guidance strategy where a goal location is defined in relation to either a coincident visual cue or a distal, visually-aligned, cue. It differs from visual guidance in the fact that the goal is recognized from essentially only one viewpoint, hence the "snapshot" analogy. As has been described in insects (see Wehner, Michel, \& Antonsen, 1996 for a review), when approaching a goal location animals employing snapshot matching must move around the goal until the live scene "matches" the stored visual representation. As described above, it is highly unlikely that our task could be solved by using a strategy such as snapshot or template matching since goal locations (1) were visibly indistinguishable from one another, and (2) had no distinct backgrounds when perceived from several different viewpoints within the arena. Moreover, as described above, children in our task never exhibited any behavior that would be indicative of snapshot matching: They never went to the center of, nor any other location within, the arena, to systematically survey the 4 or 18 potential hiding locations. Moreover, children did not systematically approach the cups from the rear of the arena (thus giving them the opportunity to visually-align cups with distal objects in front of the arena). Thus, not only is it doubtful that snapshot matching was possible in our paradigm, there is no evidence that children attempted to use any such strategy.

Finally, the role of path integration in defining spatial locations must also be considered when studying spatial memory. Path integration is the ability of animals, from insects to humans (see Etienne \& Jeffery, 2004; Wehner et al., 1996), to navigate and represent spatial locations relying only on self-motion cues (i.e., in the absence of external visual cues or other landmark cues). Although it is likely that path integration is necessary to construct an allocentric representation of the environment, the question here is whether path integration alone, in the absence of allocentric spatial processing, would allow children to solve our task. We believe that the answer to that question is "No". Children were not capable of using path integration alone to solve our task because path integration is an imprecise homing mechanism, in which error is accrued with every step and every turn (Etienne \& Jeffery, 2004). Thus, path integration appears only to guide an animal to a general area, but not to a specific location. Indeed, it has been shown that both insects and mammals need landmark confirmation, for example either coincident (i.e., visual, olfactory or tactile) or visually-aligned cues in order to discriminate the final goal location, and in absence of such cues will actually overshoot the goal (see Etienne \& Jeffery, 2004; Wehner et al., 1996, for reviews). Thus, in our 18-location paradigm, it is clear that path integration is inadequate to allow children to discriminate the rewarded locations: Theoretically, path integration may allow children to approximate the regions where they previously found rewards (although see below why we do not believe even this to be the case in our paradigm), however in order to identify which specific, visually-indistinguishable cups hide the rewards, they must recall from memory the exact spatial relations, including specific angles and distances, between the rewarded cups and distal objects in the environment to discriminate the reward locations.

Additional evidence suggests that children were unable to use path integration alone to solve the 4location task, and thus by extension, were likely unable to repeatedly approximate the general rewarded regions in the 18 cup task using path integration alone. Children between 6 and 12 months of age have been shown to be capable of using path integration to keep track of goal locations when they are passively displaced in the environment (Acredolo, 1978; Acredolo et al., 1984; Rieser \& Heiman, 1982). Moreover, Newcombe et al. (1998) showed that children's ability to find an item buried in a sandbox using path integration alone (and following self-generated movement) did not improve between 16 and 36 months. Thus, if children are capable of using path integration at such an early age, why were children in our study incapable of finding the reward location in the 4-location task before 
25 months of age? The most parsimonious explanation is that children were not capable of utilizing path integration alone to solve our task. As noted above, with time and movement, path integration coordinates are progressively degraded by the accumulation of errors (Etienne \& Jeffery, 2004), and animals must regularly update their position in the environment using a stable environmental cue (be it visual, olfactory or tactile) in order to maintain coherence between the path integrator and the real world. Indeed, it has been shown in both the hippocampus and the medial entorhinal cortex (where path integration coding may originate) that neurons normally driven by self-motion are nonetheless responsive to the displacement of distal visual cues (see Whitlock, Sutherland, Witter, Moser, \& Moser, 2008 for a review), demonstarting the highly inter-related nature of the path integration and allocentric spatial systems. Previous experiments tested path integration in young children following simple rotation and translation movements in which children were never removed from the immediate testing environment, and the time between viewing and searching was relatively short (5-10 s), likely allowing the path integrator to remain reliable (Acredolo, Pick, \& Olsen, 1975; Acredolo et al., 1984; Newcombe et al., 1998; Rieser \& Heiman, 1982). In our paradigm, however, the relatively large distances covered by the children, including multiple turns and exiting and entering from different points, and the fact that children wait out of sight of the goal locations for one minute during which time they are distracted, all likely make spatial updating necessary. And since in our paradigm the only cues available for the updating of spatial position are the distal visual objects within the environment, we can conclude that children who are capable of solving the task must be using these allocentric cues to reset their position. If children are incapable of using an allocentric representation, they will be incapable of updating their position in the arena, and thus incapable of identifying the goal locations (they are essentially constantly disoriented), which is exactly what we found with the younger children in Experiment 2.

In sum, when studying allocentric spatial memory, it is important to control for non-allocentric strategies, such as egocentric and visual guidance strategies, which may serve to guide subjects to a goal location without needing to access the allocentric spatial memory system. Principal features of our paradigm, including surrounding key parts of the arena with opaque curtains, the presence of multiple potential goal locations, and the utilization of multiple starting positions, allow these experiments to provide the strongest evidence yet for the presence of allocentric spatial memory in children from 25 month of age.

\subsection{Comparison with previous findings}

Previous studies have assessed spatial memory abilities of young children (under 5 years of age) using a variety of tasks presumed to test allocentric capacities. Although it is beyond the scope of this paper to describe in detail all of the previous results, a summary of their overall findings is appropriate. The task that has been most commonly used is the radial arm maze (Aadland et al., 1985; Foreman et al., 1984, 1990; Mandolesi et al., 2009; Overman et al., 1996). In general, studies using this task have had varying degrees of success with the youngest children (between 18 months and 3 years of age), with some studies showing above-chance performance at this age (Aadland et al., 1985; Foreman et al., 1984), and others not (Foreman et al., 1990; Mandolesi et al., 2009; Overman et al., 1996). Nevertheless, all of the studies reported that performance in the radial arm maze improves with age, and that depending on the demands of the task (free-choice versus forced-choice, trial-consistent versus trial-unique) children exhibit adult-like performance sometime between four years (Aadland et al., 1985; Foreman et al., 1990) and 6.5-8 years (Mandolesi et al., 2009; Overman et al., 1996). Other spatial memory tasks such as the Kiel locomotor task (Lehnung et al., 1998; Leplow et al., 2003), the Morris search task (Balcomb et al., 2011; Overman et al., 1996), the array rotation paradigm (Nardini et al., 2006), and an open-field task (Overman et al., 1996), have provided similar results, with the youngest children performing comparatively worse than older children, and older children attaining adult-like levels of performance between six (Nardini et al., 2006) and seven years of age (Lehnung et al., 1998; Leplow et al., 2003; Overman et al., 1996).

In contrast to previous studies, we have used within-subject analyses to determine whether or not each individual child that we tested was capable of solving an allocentric spatial memory task. In our paradigm, children two years of age and older were able to encode, remember and recall an allocentric 
representation of their environment in order to solve a spatial memory task, an age which is in general younger than the above-mentioned studies. We believe that such differences stem from four fundamentally critical components of our paradigm, which (1) does not evaluate children's capacity based on one single response (which is often the case in experiments that utilize probe trials), (2) does not require children to make a decision at a location that is not spatially coherent with the reward location (i.e., at a distance from the goal, as in the case of the radial arm maze), (3) does not require children to remember rewarded locations on a trial-unique basis (as is also often the case in radial arm maze paradigms), and (4) is free of the need for extensive language or task comprehension (as is often necessary in the case of the radial arm maze, the array rotation paradigm, and the Kiel locomotor task). Instead, our task allows children to incrementally learn about and encode the absolute position of goal locations in allocentric space, while precluding their ability to identify these locations based on the presence of coincident or aligned visual cues (in the allocentric spatial condition), or by implementing an egocentric strategy at any point during learning. Moreover, children are not required to implement a win-shift strategy, and working memory requirements are eliminated as the rewarded locations are always rewarded and the cup placed at a given location is removed once the child has searched that particular location. The combination of these factors allows children to demonstrate emergent allocentric spatial memory capacities at the earliest age possible.

As described in the Methods (Section 2.1.3), we gave specific verbal instructions ("rewards will always be found here", upon finding a reward; "rewards will never be found here" upon lifting a nonrewarded cup) and encouragement to the children who participated in our experiments. This raises the issue of whether these instructions gave an advantage to older, more linguistically-advanced children. We have previously shown that adult humans quickly and efficiently learn to solve our task without being given any verbal instructions whatsoever (Banta Lavenex \& Lavenex, 2010), demonstrating that adults will repeatedly return to locations that are consistently rewarded even in the absence of instruction to do so. However, for some tasks that require extensive and specific verbal instruction (e.g., trial-unique and forced-choice paradigms in the radial arm maze, Aadland et al., 1985; Foreman et al., 1984, 1990; Mandolesi et al., 2009; Overman et al., 1996, and the array rotation paradigm, Nardini et al., 2006), varying linguistic and intellectual capacities of children of different ages may impact their performance. In the present experiments, the successful performance of 25to 40-month-old children in the 4-location paradigm (Experiment 2), and the concomitant unsuccessful performance of 25- to 43-month-old children in the 18-location paradigm (Experiment 1), argue against the possibility that age-related differences in linguistic or general intellectual capacities were responsible for this differential performance, since the overall goals and rules of the two different paradigms were identical: "Return to where you previously found a reward". Nevertheless, it could still be argued that the reason why the youngest participants ( $<24$ months) in the 4-location paradigm were incapable of solving the task was because they did not understand the verbal instructions. However, 11 of 19 children under 24 months of age showed that they were capable of identifying the reward location in the presence of the local cue, demonstrating that they understood the overall instructions and goal of the task, and casting doubt on general linguistic or intellectual development as the critical factors(s) underlying successful performance on our task. The most parsimonious explanation suggests a graded or hierarchical development of spatial ability, where children first learn to identify locations consistently marked by local cues, and then later develop the capacity to identify static locations that are devoid of local cues by using an allocentric representation of the environment.

Previous studies have shown that by the second half of the first year ( 8.5 to 12 months) children are able to use visual guidance strategies (i.e., coincidental landmarks) to identify target locations (Acredolo, 1978; Acredolo \& Evans, 1980; Bremner, 1978b; Bushnell et al., 1995; Lew et al., 2000). It was thus surprising that in Experiment 2 (4-location task), some children between 17 and 20 months of age failed to discriminate the reward location even in the presence of the local cue. It is important to recall, however, that in our paradigm the local cue was present only on every other trial (on alternate trials a white cup was present), making this cue a reliable predictor of the reward location on only $50 \%$ of the trials. In this case, and without the ability to use allocentric cues, younger children must understand that the local cue is reliable whenever it is present. Moreover, when children enter the arena from the same side as the rewarded location (i.e., the left side when location 4 is rewarded, or the right side when location 2 is rewarded, Fig. 4), the first cups to come into their sight are always white 
cups, even during the LC condition. Thus, in order to see the red cup, children must intentionally turn to their right or their left. Our data suggest that children under 20 months of age have difficulty in organizing their search behavior to seek a local cue which is not always present or in plain sight, but that around 20 months of age, this strategy becomes accessible.

Our current results are consistent with the concept of a hierarchical development of the different types of spatial capacities in children (see Newcombe \& Huttenlocher, 2000 for a review). Egocentric capacities emerge first in the newborn child, and tend to dominate the child's spatial world for at least the first six months (Acredolo, 1978; Acredolo \& Evans, 1980; Bremner, 1978a). The use of cues or landmarks to remember spatial locations begins to appear between 8.5 and 12 months (Acredolo, 1978; Acredolo \& Evans, 1980; Bremner, 1978a; Bushnell et al., 1995; Lew et al., 2000). Path integration becomes apparent in children from 6 to 12 months of age (Acredolo, 1978; Bremner, Knowles, \& Andreasen, 1994; Rieser \& Heiman, 1982). Eventually, allocentric place learning appears to emerge around 20 months of age and is reliably expressed after two years of age (Newcombe et al., 1998; present results). Although it might seem logical to hypothesize that the emergence of certain spatial capacities would parallel motor development, with capacities such as path integration and allocentric processing emerging only once an infant can locomote and experience his environment in an autonomous manner, this view is insufficient to explain the whole developmental spectrum of spatial memory capacities observed in children, especially considering the apparent delayed emergence of allocentric capacities. Instead, as described below, we propose that the differential maturation of distinct circuits within the hippocampal formation (Jabès, Banta Lavenex, Amaral, \& Lavenex, 2011) might contribute to the gradual emergence of specific spatial memory abilities with age.

\subsection{Basic allocentric spatial memory in 2-year-old children}

Historically, the hippocampal formation, including the entorhinal cortex, the dentate gyrus, CA3, CA2, CA1, the subiculum, presubiculum and parasubiculum (Lavenex, 2012; Lavenex, Sugden, Davis, Gregg, \& Banta Lavenex, 2011), has been considered as a functional brain circuit critical for declarative and allocentric spatial memory (Milner et al., 1998; Morris, 2007; O'Keefe and Nadel, 1978; Squire, 1992). Entorhinal cortex layer II neurons project to the dentate gyrus, which projects to CA3, which projects to CA1, which projects to the subiculum and the deep layers of the entorhinal cortex, thus closing the prominent hippocampal loop of information processing known as the trisynaptic pathway. However, in addition to their primary projection toward the dentate gyrus, entorhinal cortex layer II neurons also project directly to CA3, and entorhinal cortex layer III neurons project directly to CA1 and the subiculum. Over the past decade, research in rodents has revealed that different hippocampal regions serve computationally distinct but complementary roles in the formation of these memories. For example, a basic allocentric representation of the environment can be represented in CA1 and is subserved by the direct monosynaptic pathway from the entorhinal cortex to CA1. Mizumori and colleagues first showed that CA1 place cell coding is maintained during reversible suppression of CA3 output to CA1 (Mizumori, Barnes, \& McNaughton, 1989). Brun and colleagues showed that CA1 place cell coding is maintained following direct lesion of CA3, and that behaviorally, place recognition is preserved in these animals (Brun et al., 2002). In contrast, specific lesion of the entorhinal cortex input to CA1 impairs CA1 place cell coding (Brun, Solstad, et al., 2008). Finally, transgenic mice lacking NMDA receptors in CA3 pyramidal cells, thus functionally deafferenting CA1 from its CA3 inputs, exhibit essentially normal CA1 place cells and are capable of acquiring and remembering allocentric spatial memories experienced over repeated trials (Nakazawa et al., 2002, 2003). Altogether, these experiments carried out in rodents indicate that CA1 place cell activity and a basic allocentric representation of the environment can be maintained by direct inputs from the entorhinal cortex to CA1.

Our recent analyses of the genetic and neuroanatomical development of the monkey hippocampal formation have revealed that distinct regions of the primate hippocampal formation exhibit different postnatal developmental profiles (Jabès et al., 2011; Lavenex et al., 2011). Specifically, the CA1 region of the hippocampus exhibits an early and rapid development, achieving adult-like volumes and levels of gene expression around six months of age in the macaque monkey. In contrast, the dentate gyrus and CA3 exhibit slower and prolonged developmental time courses, and do not achieve adult-like volumes or levels of gene expression until around one year of age in the macaque. Importantly, the early 
volumetric maturation of CA1 is primarily due to the early maturation of one specific layer, the stratum lacunosum-moleculare (Jabès et al., 2011), in which the direct projections from the entorhinal cortex terminate. In contrast, the remaining layers of CA1 (strata oriens, pyramidale and radiatum in which the CA3 projections terminate) exhibit a slower, protracted development (Jabès et al., 2011). If one considers that one year of life in the macaque monkey corresponds to approximately four years of life in the human (Fortman, Hewett, \& Bennett, 2002; Van Zutphen, Baumans, \& Beynen, 1993), the neuroanatomical data in monkeys suggests that CA1 likely achieves an adult-like volume around 2 years of age in the human. This corresponds precisely to the age at which we observed a qualitative shift in the spatial capacities of children, with the emergence of their ability to learn, remember and use an allocentric representation of the environment. The results of the present behavioral experiments in children, when combined with the recent anatomical data from monkeys (Jabès et al., 2011) and electrophysiological findings in rats (see above), lead us to propose that it is the maturation of the CA1 region of the hippocampus, specifically, that underlies the emergence of allocentric spatial processing that we (Experiment 2) and others (Newcombe et al., 1998) have reliably observed in children from 22 to 25 months of age.

\subsection{Improved allocentric spatial processing after 2 years of age}

We have found that children under 43 months of age were not capable of solving a complex allocentric spatial memory task that required discriminating three reward locations from among 18 spatially distinct locations (Experiment 1), although children of this same age were capable of using an allocentric representation to discriminate one reward location amongst four possible locations (Experiment 2). As described above, a direct projection from the entorhinal cortex to CA1 is thought to be able to subserve basic allocentric spatial processing. In contrast, computational models and a number of in vivo studies support the hypothesis that the dentate gyrus, together with its connections with CA3, subserve a process known as pattern separation (Bakker, Kirwan, Miller, \& Stark, 2008; Brun, Leutgeb, et al., 2008; Gilbert, Kesner, \& DeCoteau, 1998; Gilbert, Kesner, \& Lee, 2001; Kesner, 2007; Leutgeb, Leutgeb, Moser, \& Moser, 2007; Leutgeb \& Leutgeb, 2007; Nakashiba, Young, McHugh, Buhl, \& Tonegawa, 2008; Nakazawa et al., 2002), which might be necessary to discriminate individual items, episodes or spatial locations that are very similar or close to one another (Brun, Leutgeb, et al., 2008; Kesner, 2007; Leutgeb et al., 2007; Morris, Churchwell, Kesner, \& Gilbert, 2012; Rolls, 2008). In accordance with this hypothesis, studies have shown that disrupting the CA3 input to CA1 results in decreased spatial tuning of CA1 place cells (Brun et al., 2002; Nakashiba et al., 2008), thus suggesting the necessity of the main trisynaptic hippocampal pathway (i.e., entorhinal cortex to dentate gyrus, dentate gyrus to CA3, CA3 to CA1) for maintaining high-resolution spatial discrimination (i.e., spatial pattern separation).

Recent work in our laboratory has shown that the monkey dentate gyrus, in which nearly $40 \%$ of the neurons found in the adult are generated postnatally (Jabès, Banta Lavenex, Amaral, \& Lavenex, 2010), exhibits a late and protracted development, and has not yet reached an adult volume at one year of age (which corresponds to approximately 4 years of age in humans). This lead us to hypothesize that the improvement in allocentric spatial memory capacities with age might result from the gradual functional maturation of the dentate gyrus and trisynaptic hippocampal pathway, which contribute to improved spatial pattern separation abilities from 2 to 6 years of life in humans. Indeed, studies of both spatial and autobiographical episodic memories suggest that these forms of hippocampal-dependent memory mature significantly within the same age range (Acredolo et al., 1975; Balcomb et al., 2011; Bauer, 2007; Herman \& Siegel, 1978; Newcombe \& Huttenlocher, 2000; Sluzenski, Newcombe, \& Satlow, 2004).

The results of a previous study are in agreement with our proposed hypothesis that the improvements that occur in children's allocentric spatial memory after 2 years of age (i.e., after the basic capacity to learn and remember an allocentric representation of the environment has emerged) correspond to improvements in children's ability to more precisely calculate the spatial coordinates of individual locations based on distal environmental objects (Acredolo et al., 1975). They showed that, under five years of age, the accuracy of children to replace items where they found them improved when landmarks were located close to the target locations, whereas the performance of older children 
was already optimal in absence of adjacent landmarks. Age-dependent maturation in spatial pattern separation capacities can also explain the age-dependent improvements in children's performance in tasks such as the Morris search task (Overman et al., 1996), the radial arm maze (Aadland et al., 1985; Foreman et al., 1984, 1990; Overman et al., 1996), open-field tasks (Overman et al., 1996), and sandbox search tasks that test children's representation of multiple locations, relations between objects, and short-term (2 min) retention of a spatial location (Sluzenski et al., 2004).

\subsection{The emergence of autobiographical memory in 2-year-old children}

The lack of autobiographical memories from our infancy has often been hypothesized to result from the immaturity of the neurobiological substrates subserving these memories in adult individuals (see Bauer, 2007; Newcombe et al., 2007 for reviews), although concrete neurobiological evidence for these theories has been notably absent. We have shown that from 2 years of age, children are capable of solving a spatial task using a basic allocentric representation of the surrounding environment. The emergence of this capacity coincides temporally with the end of infantile amnesia, and as we have proposed, likely coincides with the structural and functional maturation of the CA1 region of the hippocampus (Jabès et al., 2011).

We have also shown that by 3.5 years of age, children are capable of solving a complex allocentric spatial task, which necessitates a high degree of spatial pattern separation in order to discriminate goal locations from closely apposed decoy locations. This capacity likely coincides with the structural and functional maturation of the dentate gyrus and trisynaptic hippocampal pathway (see above). However, it has also been recently shown that the trisynaptic pathway is critical for rapid single-trial contextual learning (Nakashiba et al., 2003, 2008). The encoding of autobiographical memories, by definition, requires rapid, single-trial contextual learning. We therefore propose that it is the immaturity of the dentate gyrus (Jabès et al., 2010, 2011) that underlies the phenomenon of childhood amnesia, and the gradual maturation of the trisynaptic hippocampal pathway subserves the gradual improvement, from 2 to 7 years of age, in our ability to create autobiographical memories that can be recalled later in life.

In sum, it is highly probable that a causal relationship between the structural and functional maturation of the hippocampal formation and infantile and childhood amnesia exists. Future research should prioritize investigations of the relationships between the maturation of specific hippocampal circuits and the development of high-resolution allocentric spatial representations, single-trial contextual learning and the emergence of autobiographical memory in children and experimental animals.

\section{Conclusion}

We found that the ability to form a basic allocentric representation of the environment is present by 2 years of age; its emergence coincides temporally with the offset of infantile amnesia. However, the ability of children to distinguish and remember closely related spatial locations improves from 2 to 3.5 years of age, a developmental period marked by persistent deficits in long-term episodic memory known as childhood amnesia. Our findings are consistent with the hypothesis that the differential maturation of distinct hippocampal circuits contributes to the emergence of specific memory processes during early childhood. A theoretical framework in which both the discrete functions of different regions of the hippocampal formation and their differential developmental time courses are considered represents a fundamental shift in how the development of allocentric spatial memory abilities can be conceptualized, and provides strong evidence against the persistent idea that poorer spatial performance in children under 7 years of age reflects a generalized lack of allocentric spatial capacities.

\section{Funding sources}

This research was supported by the Swiss National Science Foundation: Grants PP00A-106701, PP00P3-124536 to PL and Grants PMPDP3-122844, PMPDP3-128996 to PBL. The Swiss National Sci- 
ence Foundation had no involvement in the study design, nor in the collection, analysis or interpretation of the data, nor in the writing of this report or the decision to submit it for publication. The authors have no conflicts of interest to declare.

\section{Acknowledgments}

The authors would like to thank all of the children and their families who participated in this study. We also thank Jane Favre and Typhaine Juvet for their help testing participants.

\section{References}

Aadland, J., Beatty, W. W., \& Maki, R. H. (1985). Spatial memory of children and adults assessed in the radial maze. Developmental Psychobiology, 18(2), 163-172.

Acredolo, L. P. (1977). Developmental changes in the ability to coordinate perspectives of a large-scale space. Developmental Psychology, 13(1), 1-8.

Acredolo, L. P. (1978). Development of spatial orientation in infancy. Developmental Psychology, 14(3), 224-234.

Acredolo, L. P., Adams, A., \& Goodwyn, S. (1984). The role of self-produced movement and visual tracking in infant spatial orientation. Journal of Experimental Child Psychology, 38, 312-327.

Acredolo, L. P., \& Evans, D. (1980). Developmental changes in the effects of landmarks on infant spatial behavior. Developmental Psychology, 16(4), 312-318.

Acredolo, L. P., Pick, H. L., \& Olsen, M. G. (1975). Environmental differentiation and familiaritiy as determinants of children's memory for spatial location. Developmental Psychology, 11(4), 495-501.

Bachevalier, J. (1992). Cortical versus limbic immaturity: Relationship to infantile amnesia. In M. R. Gunnar \& C. A. Nelson (Eds.), Developmental behavioral neuroscience: The minnesota symposia on child psychology. Minnesota symposia on child psychology series (Vol. 24, pp. 129-152). New Jersey: Laurence Erlbaum Associates.

Bakker, A., Kirwan, C. B., Miller, M., \& Stark, C. E. (2008). Pattern separation in the human hippocampal CA3 and dentate gyrus. Science, 319(5870), 1640-1642.

Balcomb, F., Newcombe, N. S., \& Ferrara, K. (2011). Finding where and saying where: Developmental relationships between place learning and language in the first year. Journal of Cognition and Development, 12, 315-331.

Banta Lavenex, P., Amaral, D. G., \& Lavenex, P. (2006). Hippocampal lesion prevents spatial relational learning in adult macaque monkeys. Journal of Neuroscience, 26(17), 4546-4558.

Banta Lavenex, P., \& Lavenex, P. (2009). Spatial memory and the monkey hippocampus: Not all space is created equal. Hippocampus, 19(1), 8-19.

Banta Lavenex, P., \& Lavenex, P. (2010). Spatial relational learning and memory abilities do not differ between men and women in a real-world, open-field environment. Behavioural Brain Research, 207(1), 125-137.

Bauer, P. J. (2007). Remembering the times of our lives: Memory in infancy and beyond. New York: Laurence Erlbaum and Associates.

Bremner, J. G. (1978a). Egocentric versus allocentric spatial coding in nine-month-old infants: Factors influencing the choice of code. Developmental Psychology, 14(4), 346-355.

Bremner, J. G. (1978b). Spatial errors made by infants: Inadequate spatial cues or evidence of egocentrism? British Journal of Psychology, 1978(69), 1

Bremner, J. G., \& Bryant, P. E. (1977). Place versus response as the basis of spatial errors made by young infants. Journal of Experimental Child Psychology, 23, 162-171.

Bremner, J. G., Knowles, L., \& Andreasen, G. (1994). Processes underlying young children's spatial orientation during movement. Journal of Experimental Child Psychology, 57, 355-376.

Brun, V. H., Leutgeb, S., Wu, H. Q., Schwarcz, R., Witter, M. P., Moser, E. I., et al (2008). Impaired spatial representation in CA1 after lesion of direct input from entorhinal cortex. Neuron, 57(2), 290-302.

Brun, V. H., Otnass, M. K., Molden, S., Steffenach, H. A., Witter, M. P., Moser, M. B., et al (2002). Place cells and place recognition maintained by direct entorhinal-hippocampal circuitry. Science, 296(5576), 2243-2246.

Brun, V. H., Solstad, T., Kjelstrup, K. B., Fyhn, M., Witter, M. P., Moser, E. I., et al (2008). Progressive increase in grid scale from dorsal to ventral medial entorhinal cortex. Hippocampus, 18(12), 1200-1212.

Bullens, J., Nardini, M., Doeller, C. F., Braddick, O., Postma, A., \& Burgess, N. (2010). The role of landmarks and boundaries in the development of spatial memory. Developmental Science, 13(1), 170-180.

Bushnell, E. W., McKenzie, B. E., Lawrence, D. A., \& Connell, S. (1995). The spatial coding strategies of one-year-old infants in a locomotor search task. Child Development, 66(4), 937-958.

Cahill, L., McGaugh, J. L., \& Weinberger, N. M. (2001). The neurobiology of learning and memory: Some reminders to remember. Trends in Neurosciences, 24(10), 578-581.

Cornell, E. H., \& Heth, C. D. (1979). Response versus place learning by human infants. Journal of Experimental Psychology, 5(2), $188-196$.

Cornell, E. H., Heth, C. D., Broda, L. S., \& Butterfield, V. (1987). Spatial matching in $11 / 2$ - to $41 / 2$-year-old children. Developmental Psychology, 23(4), 499-508.

DeLoache, J. S., \& Brown, A. L. (1983). Very young children's memory for the location of objects in a large-scale environment. Child Development, 54, 888-897.

Dempster, F. N. (1981). Memory span: Sources of individual and developmental differences. Psychological Bulletin, 89(1), 63-100.

Eichenbaum, H., Stewart, C., \& Morris, R. G. M. (1990). Hippocampal representation in place learning. Journal of Neuroscience, 10(11), 3531-3542. 
Etienne, A. S., \& Jeffery, K. J. (2004). Path integration in mammals. Hippocampus, 14, 180-192.

Foreman, N., Arber, M., \& Savage, J. (1984). Spatial memory in preschool infants. Developmental Psychobiology, 17(2), $129-137$.

Foreman, N., Warry, R., \& Murray, P. (1990). Development of reference and working spatial memory in preschool children. Journal of General Psychology, 117(3), 267-276.

Fortman, J. D., Hewett, T. A., \& Bennett, B. T. (2002). The laboratory nonhuman primate. Boca Raton: CRC Press.

Gaffan, E. A., \& Davies, J. (1981). The role of exploration and win-shift and win-stay performance on a radial maze. Learning and Motivation, 12, 282-299.

Gallistel, C. R. (1990). The organization of learning. Cambridge, MA: MIT Press.

Gathercole, S. E. (1998). The development of memory. Journal of Child Psychology and Psychiatry, 39(1), 3-27.

Gilbert, P. E., Kesner, R. P., \& DeCoteau, W. E. (1998). Memory for spatial location: Role of the hippocampus in mediating spatial pattern separation. Journal of Neuroscience, 18(2), 804-810.

Gilbert, P. E., Kesner, R. P., \& Lee, I. (2001). Dissociating hippocampal subregions: Double dissociation between dentate gyrus and CA1. Hippocampus, 11(6), 626-636.

Herman, J. F., \& Siegel, A. W. (1978). The development of cognitive mapping of the large-scale environment. Journal of Experimental Child Psychology, 26, 389-406.

Hitch, G. J., \& Halliday, M. S. (1983). Working memory in children. Philosophical Transactions of the Royal Society of London. Series B, Biological sciences, 302(1110), 325-340.

Jabès, A., Banta Lavenex, P., Amaral, D. G., \& Lavenex, P. (2010). Quantitative analysis of postnatal neurogenesis and neuron number in the macaque monkey dentate gyrus. European Journal of Neuroscience, 31(2), 273-285.

Jabès, A., Banta Lavenex, P., Amaral, D. G., \& Lavenex, P. (2011). Postnatal development of the hippocampal formation: A stereological study in macaque monkeys. Journal of Comparative Neurology, 519(6), 1051-1070.

Kesner, R. P. (2007). A behavioral analysis of dentate gyrus function. Progress in Brain Research, 163, 567-576.

Konkel, A., \& Cohen, N. J. (2009). Relational memory and the hippocampus: Representations and methods. Frontiers in Neuroscience, 3(2), 166-174.

Lavenex, P. (2012). Functional anatomy, development and pathology of the hippocampus. In T. Bartsch (Ed.), The Clinical Neurobiology of the Hippocampus: An integrative view (pp. 10-38). Oxford: Oxford University Press.

Lavenex, P., \& Banta Lavenex, P. (2006). Spatial relational memory in 9-month-old macaque monkeys. Learning \& Memory, 13(1), 84-96.

Lavenex, P., Banta Lavenex, P., \& Amaral, D. G. (2007). Spatial relational learning persists following neonatal hippocampal lesions in macaque monkeys. Nature Neuroscience, 10(2), 234-239.

Lavenex, P., \& Schenk, F. (1995). Influence of local environmental olfactory cues on place learning in rats. Physiology \& Behavior, 58(6), 1059-1066.

Lavenex, P., \& Schenk, F. (1996). Integration of olfactory information in a spatial representation enabling accurate arm choice in the radial arm maze. Learning \&' Memory, 2(6), 299-319.

Lavenex, P., \& Schenk, F. (1997). Olfactory cues potentiate learning of distant visuospatial information. Neurobiology of Learning and Memory, 68(2), 140-153.

Lavenex, P., \& Schenk, F. (1998). Olfactory traces and spatial learning in rats. Animal Behaviour, 56, 1129-1136.

Lavenex, P., Shiflett, M. W., Lee, R. K., \& Jacobs, L. F. (1998). Spatial versus nonspatial relational learning in free-ranging fox squirrels (Sciurus niger). Journal of Comparative Psychology, 112(2), 127-136.

Lavenex, P., Sugden, S. G., Davis, R. R., Gregg, J. P., \& Banta Lavenex, P. (2011). Developmental regulation of gene expression and astrocytic processes may explain selective hippocampal vulnerability. Hippocampus, 21(2), 142-149.

Lehnung, M., Leplow, B., Friege, L., Herzog, A., Ferstl, R., \& Mehdorn, M. (1998). Development of spatial memory and spatial orientation in preschoolers and primary school children. British Journal of Psychology, 89(Pt 3), 463-480.

Leplow, B., Lehnung, M., Pohl, J., Herzog, A., Ferstl, R., \& Mehdorn, M. (2003). Navigational place learning in children and young adults as assessed with a standardized locomotor search task. British Journal of Psychology, 94(Pt 3), 299-317.

Leutgeb, S., \& Leutgeb, J. K. (2007). Pattern separation, pattern completion, and new neuronal codes within a continuous CA3 map. Learning \& Memory, 14(11), 745-757.

Leutgeb, J. K., Leutgeb, S., Moser, M. B., \& Moser, E. I. (2007). Pattern separation in the dentate gyrus and CA3 of the hippocampus. Science, 315(5814), 961-966.

Lew, A. R., Bremner, J. G., \& Lefkovitch, L. P. (2000). The development of relational landmark use in six- to twelve-month-old infants in a spatial orientation task. Child Development, 71(5), 1179-1190.

Mandolesi, L., Petrosini, L., Menghini, D., Addona, F., \& Vicari, S. (2009). Children's radial arm maze performance as a function of age and sex. International Journal of Developmental Neuroscience, 27(8), 789-797.

Milner, B., Squire, L. R. \& Kandel, E. R. (1998). Cognitive neuroscience and the study of memory. Neuron, 20(3), 445-468.

Mizumori, S. J., Barnes, C. A., \& McNaughton, B. L. (1989). Reversible inactivation of the medial septum: Selective effects on the spontaneous unit activity of different hippocampal cell types. Brain Research, 500(1-2), 99-106.

Morris, R. G. M. (2007). Theories of hippocampal function. In P. Anderson, R. G. M. Morris, D. G. Amaral, T. V. Bliss, \& J. O’Keefe (Eds.), The hippocampus book (pp. 581-713). Oxford: Oxford University Press.

Morris, A. M., Churchwell, J. C., Kesner, R. P., \& Gilbert, P. E. (2012). Selective lesions of the dentate gyrus produce disruptions in place learning for adjacent spatial locations. Neurobiology of Learning and Memory, 97(3), 326-331.

Morris, R. G., Garrud, P., Rawlins, J. N., \& O’Keefe, J. (1982). Place navigation impaired in rats with hippocampal lesions. Nature, 297(5868), 681-683.

Nadel, L., \& Zola-Morgan, S. (1984). Infantile amnesia: A neurobiological perspective. In M. Moscovitch (Ed.), Infant memory. New York: Plenum Press.

Nakashiba, T., Young, J. Z., McHugh, T. J., Buhl, D. L., \& Tonegawa, S. (2008). Transgenic inhibition of synaptic transmission reveals role of CA3 output in hippocampal learning. Science, 319(5867), 1260-1264.

Nakazawa, K., Quirk, M. C., Chitwood, R. A., Watanabe, M., Yeckel, M. F., Sun, L. D., et al (2002). Requirement for hippocampal CA3 NMDA receptors in associative memory recall. Science, 297(5579), 211-218.

Nakazawa, K., Sun, L. D., Quirk, M. C., Rondi-Reig, L., Wilson, M. A., \& Tonegawa, S. (2003). Hippocampal CA3 NMDA receptors are crucial for memory acquisition of one-time experience. Neuron, 38(2), 305-315. 
Nardini, M., Burgess, N., Breckenridge, K., \& Atkinson, J. (2006). Differential developmental trajectories for egocentric, environmental and intrinsic frames of reference in spatial memory. Cognition, 101(1), 153-172.

Newcombe, N. S., \& Huttenlocher, J. (2000). Making space. The development of spatial representation and reasoning. Cambridge, MA: MIT Press.

Newcombe, N. S., Huttenlocher, J., Bullock Drummey, A., \& Wiley, J. G. (1998). The development of spatial coding: Place learning and dead reckoning in the second and third years. Cognitive Development, 13, 185-200.

Newcombe, N., Lloyd, M. E., \& Ratliff, K. R. (2007). Development of episodic and autobiographical memory: A cognitive neuroscience perspective. Advances in Child Development and Behavior, 35, 37-85.

Nyberg, L., McIntosh, A. R., Cabeza, R., Habib, R., Houle, S., \& Tulving, E. (1996). General and specific brain regions involved in encoding and retrieval of events: What, where, and when. Proceedings of the National Academy of Sciences USA, 93(20), $11280-11285$.

O’Keefe, J., \& Nadel, L. (1978). The hippocampus as a cognitive map. Oxford University Press.

Olton, D. S., Walker, J. A., \& Gage, F. H. (1978). Hippocampal connections and spatial discrimination. Brain Research, 139(2), 295-308.

Overman, W. H., Pate, B. J., Moore, K., \& Peuster, A. (1996). Ontogeny of place learning in children as measured in the radial arm maze, Morris search task, and open field task. Behavioral Neuroscience, 110(6), 1205-1228.

Pentland, L. M., Anderson, V. A., Dye, S., \& Wood, S. J. (2003). The nine box maze test: A measure of spatial memory development in children. Brain and Cognition, 52(2), 144-154.

Pepperberg, I. M. (1981). Functional vocalizations by an African grey parrot (Psittacus erithacus). Zeitschrift Tierpsychologie, 55, $139-160$

Place, R., Lykken, C., Beer, Z., Suh, J., McHugh, T. J., Tonegawa, S., et al (2012). NMDA signaling in CA1 mediates selectively the spatial component of episodic memory. Learning \& Memory, 19(4), 164-169.

Pravosudov, V. V., Lavenex, P., \& Omanska, A. (2005). Nutritional deficits during early development affect hippocampal structure and spatial memory later in life. Behavioral Neuroscience, 119(5), 1368-1374.

Rieser, J. J. (1979). Spatial orientation of six-month-old infants. Child Development, 50, 1078-1087.

Rieser, J. J., \& Heiman, M. L. (1982). Spatial self-reference systems and shortest-route behavior in toddlers. Child Development, 53. 524-533.

Rogers, J. L., \& Kesner, R. P. (2006). Lesions of the dorsal hippocampus or parietal cortex differentially affect spatial information processing. Behavioral Neuroscience, 120(4), 852-860.

Rolls, E. T. (2008). Computational models of hippocampal functions. In J. Byrne (Ed.), Learning theory and behavior (pp. 641-666). Oxford: Elsevier.

Rudy, J. W. (2008). The neurobiology of learning and memory. Sunderland, MA: Sinauer Associates, Inc.

Siegel, L. S., \& Ryan, E. B. (1989). The development of working memory in normally achieving and subtypes of learning disabled children. Child Development, 60(4), 973-980.

Sluzenski, J., Newcombe, N. S., \& Satlow, E. (2004). Knowing where things are in the second year of life: Implications for hippocampal development. Journal of Cognitive Neuroscience, 16(8), 1443-1451.

Smith, A. D., Gilchrist, I. D., Cater, K., Ikram, N., Nott, K., \& Hood, B. M. (2008). Reorientation in the real world: The development of landmark use and integration in a natural environment. Cognition, 107(3), 1102-1111.

Squire, L. R. (1992). Memory and the hippocampus: A synthesis from findings with rats, monkeys, and humans. Psychological Review, 99(2), 195-231.

Tolman, E. C., \& Honzik, C. H. (1930). Introduction and removal of reward, and maze performance in rats. University of California Publications in Psychology, 4, 257-275.

Tulving, E. (2002). Episodic memory: From mind to brain. Annual Review of Psychology, 53, 1-25.

Tyler, D., \& McKenzie, B. E. (1990). Spatial updating and training effects in the first year of human infancy. Journal of Experimental Child Psychology, 50, 445-461.

Van Zutphen, L. F. M., Baumans, V., \& Beynen, A. C. (1993). Principles of laboratory animal science. Amsterdam: Elsevier.

Wehner, R., Michel, B., \& Antonsen, P. (1996). Visual navigation in insects: Coupling of egocentric and geocentric information. Journal of Experimental Biology, 199(Pt 1), 129-140.

Weniger, G. \& Irle, E. (2006). Posterior parahippocampal gyrus lesions in the human impair egocentric learning in a virtual environment. European Journal of Neuroscience, 24(8), 2406-2414.

Weniger, G., Ruhleder, M., Wolf, S., Lange, C., \& Irle, E. (2009). Egocentric memory impaired and allocentric memory intact as assessed by virtual reality in subjects with unilateral parietal cortex lesions. Neuropsychologia, 47(1), 59-69.

White, N. M., \& McDonald, R. J. (2002). Multiple parallel memory systems in the brain of the rat. Neurobiology of Learning and Memory, 77(2), 125-184.

Whitlock, J. R., Sutherland, R. J., Witter, M. P., Moser, M.-B., \& Moser, E. I. (2008). Navigating from hippocampus to parietal cortex. Proceedings of the National Academy of Sciences, 105(39), 14755-14762. 